\title{
A Bracket-Stiffened Two-Planar Overlapped Tubular KT-Joint for Offshore Jack-Up Fatigue Analysis
}

\author{
Jian Zhang $D^{1},{ }^{1}$ Xinxin Yue, ${ }^{1}$ Jiajia Qiu, ${ }^{1}$ Lei Chen, ${ }^{1}$ and Wei Shen ${ }^{2}$ \\ ${ }^{1}$ Department of Mechanics and Engineering Science, Jiangsu University, Zhenjiang 212013, China \\ ${ }^{2}$ Centre for Offshore Research and Engineering, Department of Civil and Environmental Engineering, \\ National University of Singapore, 1 Engineering Drive 2, 117576, Singapore \\ Correspondence should be addressed to Jian Zhang; jianzhang@u.nus.edu
}

Received 16 September 2020; Revised 9 March 2021; Accepted 12 March 2021; Published 23 March 2021

Academic Editor: Melina Bosco

Copyright ( $\odot 2021$ Jian Zhang et al. This is an open access article distributed under the Creative Commons Attribution License, which permits unrestricted use, distribution, and reproduction in any medium, provided the original work is properly cited.

There have been a large number of research programs dedicated to the investigation of stress concentration factor and its parametric design formulae for a variety of uniplanar and multiplanar tubular joints. However, for the multiplanar overlapped tubular joints, the related reports are very limited due to the fact that the combining effect between multiplanarity and brace overlapping is quite complex. In this paper, a novel bracket-stiffened two-planar overlapped tubular KT-joint is proposed by adding two brackets between the upper diagonal and horizontal braces to alleviate the stress concentration at the brace-to-chord intersection area. As compared with the original KT-joint and KT-joint of larger brace gap, stress concentration reduction and fatigue strength enhancement at the most critical point of the proposed KT-joint are significant under both axial and in-plane bending (IPB) loads. The superiority of the proposed KT-joint is further tested with a simplified fatigue life assessment of offshore jack-up in field transit condition, when the KT-joint corresponding to the upper guide level is most critical and fatigue-sensitive. The obtained results with conservative assumptions may serve as guides or references in civil and offshore engineering practices.

\section{Introduction}

Circular hollow section (CHS) members are widely used as the primary components in civil and offshore engineering structures, such as jack-ups [1] as shown in Figure 1(a), due to high strength-to-weight ratio and low drag coefficient. A tubular joint is formed by joining the CHS members in which the profiled ends of brace members are welded onto the circumference of the chord member. Cyclic wave loading on offshore tubular joints may induce localized fatigue damage and failure due to high stress concentration at the vicinity of brace-to-chord intersections. For the purpose of fatigue design, the stress concentration factor (SCF), defined as the ratio of the local surface stress at the brace-to-chord intersection to the nominal stress in the brace [2], is used to quantify stress concentrations at various locations around the welded region. Therefore, accurate estimation of the SCFs for tubular joints is of great importance to the fatigue life prediction of civil and offshore structures.
For the past few decades, there have been quite a number of research programs devoted to the study of SCF values and parametric design formulae for various uniplanar tubular joints [3-11] and recently for reinforced tubular joints [12-14]. On the other hand, as multiplanar tubular joints dominate the practical applications for offshore structures, multiplanarity effects are important in determining the stress distribution at the vicinity of joint intersection. Thus, the parametric formulae of uniplanar tubular joints for SCF prediction may not be suitable for such multiplanar connections. Due to the complexity and high cost involved, however, there have been much fewer research efforts on multiplanar tubular joints, such as Karamanos et al. [15] and Chiew et al. [16] for SCF parametric equations in XX-joints; Karamanos et al. [17, 18] and Jiang et al. [19] for SCF prediction in DT-joints under axial and bending loads, respectively; van Wingerde et al. [20] and Woghiren and Brennan [21] for SCF determination in KK-joints; and Ahmadi et al. [22], Ahmadi et al. [23], and Ahmadi and 


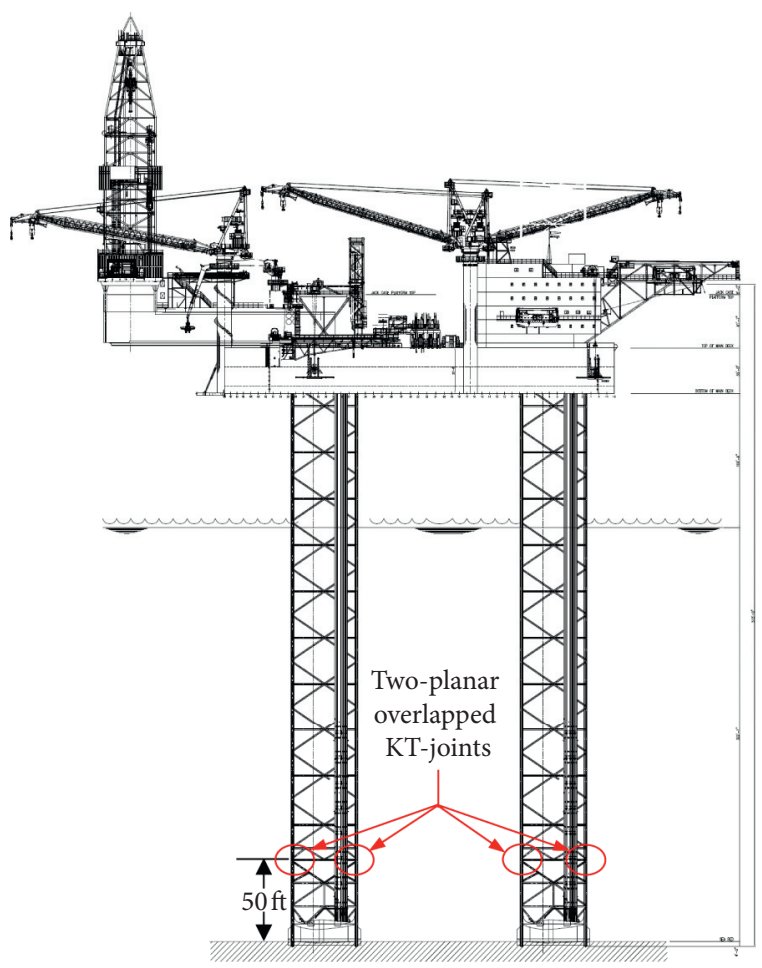

(a)

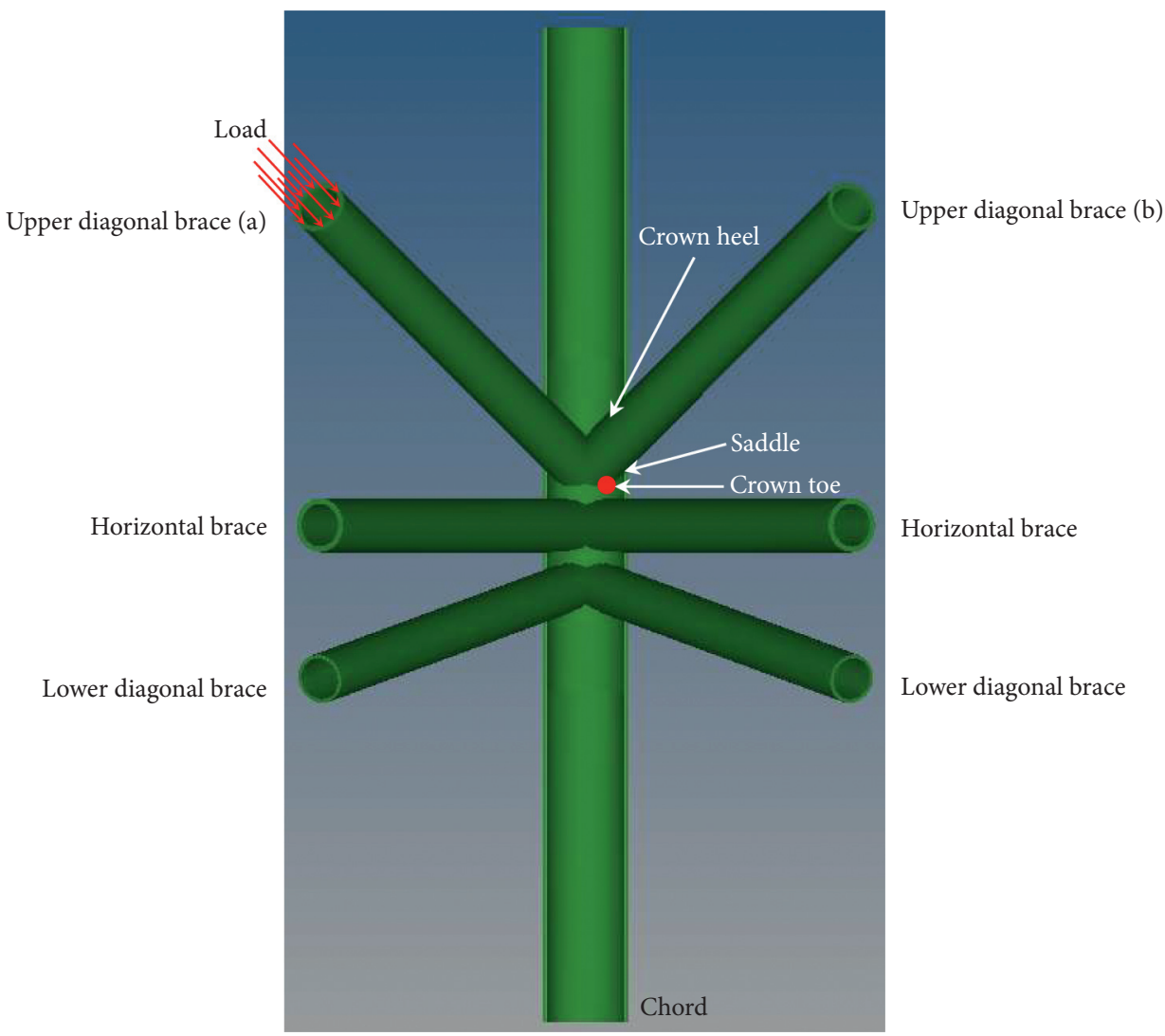

(c)

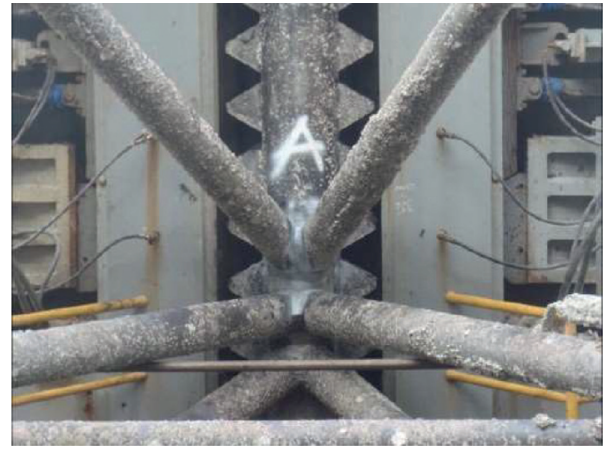

(b) 
Zavvar [24] for SCF design formulae and multiplanarity in KT-joints.

As nonoverlapped tubular joints [2] are easy to fabricate and numerous techniques have been developed for assessing their strength and fatigue performances [4, 5, 8-24], they are widely used in the construction of many tubular structures. However, when the brace-to-chord diameter ratio $(\beta)$ is bigger than 0.6 , nonoverlapped tubular joints may not be easily designed due to the limited range of geometric validity in many design codes $[25,26]$. Instead, an overlapped joint may be needed, which can be either in-plane (the chord axis is in the same plane with the axes of overlapped braces) or out-of-plane (the chord axis is in a plane different from the axes of overlapped braces). Due to more complex intersection profile and construction procedure, an overlapped CHS joint generally has a higher fabrication cost than a nonoverlapped joint. However, an overlapped CHS joint outperforms its nonoverlapped counterpart in terms of eccentricity/unbalance elimination [27], cost-effectiveness [28], and ultimate strength capacity [29]. In the context of SCF and fatigue performance for overlapped tubular joints, Efthymiou and Durkin [3] developed the SCF equations for partially overlapped $\mathrm{K}$-joints based on a small-scale finite element study. Their equations were validated experimentally by Dharmavasan and Seneviratne [30], and it was found that overlapping helps reduce the chord SCFs. Lee et al. [27] carried out full-scale tests on overlapped K-joints and found that the SCF formulae by Ethymiou and Durkin [3] are conservative for the joints subjected to IPB loads, but not for the case of axial loads. Lee et al. [31] compared the fatigue performances of nonoverlapped and partially overlapped $\mathrm{K}$-joints under different loading conditions and concluded that a partially overlapped $\mathrm{K}$-joint is superior to its nonoverlapped counterpart as most of the members in actual truss design are assumed to be axially loaded only. Other investigations include fatigue behavior of overlapped tubular joints with an overlapping ratio (i.e., the overlapped length to the brace diameter) larger than $50 \%[6,7,32]$, hysteretic behavior of reinforced overlapped joints [33], and local joint flexibility and strength of overlapped tubular joints [34-36].

From the preceding discussion, it can be concluded that the research efforts on the overlapped tubular joints expanded so far are mainly for uniplanar K-joints with inplane overlapping [3, 6, 7, 27-32]. Recently, Zhang et al. [37] proposed a framework to derive the unified SCF values in multiplanar overlapped tubular KK-joints using an equivalent beam stick model and basic loading cases. Other than this, to the best of the authors' knowledge, there is no report on the SCF and fatigue performance of multiplanar overlapped tubular joints in which the axis of the chord member resides in a plane different from the axes of overlapped brace members. The major challenges may lie in two aspects: (1) multiplanar overlapped tubular joints normally involve outof-plane overlapping, and (2) the combining effect between multiplanarity and brace overlapping is quite complex.

To tackle the above challenges, a bracket-stiffened twoplanar overlapped tubular KT-joint for offshore jack-up fatigue analysis is proposed in this paper. By adding two brackets between the upper diagonal and horizontal braces for stress concentration alleviation at the vicinity of braceto-chord intersections, a novel bracket-stiffened overlapped KT-joint is firstly developed. Performances of the proposed KT-joint in stress concentration reduction and fatigue strength enhancement are then investigated and compared with the original KT-joint and KT-joint with larger brace gap under different loading conditions. Taking jack-up leg structures with the proposed KT-joint in field transit condition as an example, a simplified fatigue life assessment is lastly performed based on random wave scatter data in the North Atlantic. Hot spot stress method is employed for the critical points at the concerned bracket-stiffened KT-joint. Recommendation for further improving the fatigue behavior of the proposed KT-joint is also provided.

\section{Bracket-Stiffened Two-Planar Overlapped KT-Joint}

2.1. Background. Offshore jack-up is a mobile self-elevating drilling unit used for oil and gas exploration in shallow sea. It is typically composed of a buoyant and approximately triangular hull supported by three lattice legs, each residing on a large inverted conical footing (also called spudcan). As an integral part of the jack-up lattice legs, the two-planar overlapped KT-joints under investigation are at an elevation of around 50 feet (see Figure 1(a)), which corresponds to the upper guide level of the jack-up in the field transit condition. The detailed view of a fabricated two-planar overlapped KTjoint is shown in Figure 1(b). It can be observed that the axes of the chord and overlapping braces are in two different planes.

For fatigue design of nonoverlapped tubular joints, the hot spot stress at the brace-to-chord intersection is calculated as the nominal stress in the brace multiplied by appropriate SCFs [2]. Carry-over effect is defined as the stress concentration at a certain location near the weld toe due to a load (axial or bending) on another brace. Referring to the joint of Figure 1(c), the local stress at a weld location of upper diagonal brace (b) due to a load on upper diagonal brace (a) is a "carry-over effect." In such a case, upper diagonal brace (b) is called the "reference brace," while upper diagonal brace (a) is the "carry-over brace." According to the investigations by Karamanos et al. [17, 18] for multiplanar nonoverlapped tubular joints, stress concentrations due to carry-over effects can be neglected at crown locations of the reference brace for both axial and bending cases. However, due to the overlapping effect, stress concentrations should be considered at crown locations of the reference brace [37], for example, the crown toe and crown heel of upper diagonal brace (b) as depicted in Figure 1(c).

2.2. Local Finite Element Analysis. Since no parametric SCF equations are available for two-planar overlapped tubular KT-joints, the SCF values are often determined by using finite element (FE) analysis. A detailed FE joint model with 20-node solid (brick) elements was analyzed in ANSYS 15.0 [38] to determine the SCFs for the chord and braces of the concerned KT-joints. Linear elastic material properties are 
defined for both the chord and braces with steel density of $490 \mathrm{lb} / \mathrm{ft}^{3}$, Young's modulus of $29000 \mathrm{ksi}$, and Poisson's ratio of 0.3 . The structural dimension and yield strength of the joint model are presented in Table 1. To obtain an accurate prediction of acting stress gradients in the local model, a very fine mesh with element size of 0.625 to 1.25 inches has been used on regions around the connection between the chord and braces, while areas away from the connection can have larger element size up to 5.5 inches, as shown in Figure 2(a). Both ends of the chord are fixed. The extent of the local model has to be chosen such that the effect of the boundaries on the considered structural responses (e.g., stress magnitude) is sufficiently small. As pointed out by Prastianto et al. [39], the ratio of chord length to chord radius $(\alpha)$ should be greater than 12. In this study, a parameter value of $\alpha=30$ is conservatively assigned to the local model. As the local joint model will be used for jack-up fatigue analysis in the field transit condition (see Section 3), the translational degrees of freedom (DOF) of chord rack against the upper guide are constrained along the guide height.

SCF is defined as the ratio of the hot spot stress at a location to the nominal stress computed for that location. The hot spot stress from the FE analysis is calculated using a linear extrapolation scheme, where the "reference" stresses at each of the two locations adjacent to the hot spot location are extrapolated to the hot spot. For a tubular joint, the two locations where the stresses should be obtained for extrapolation to the hot spot location at the weld toe are provided in DNVGL-RP-C203 [40]. The extrapolated component stresses are then used to compute the maximum principal stress at the weld toe to determine the SCF. Note that the effect of weld geometry on the SCFs is not considered in this study. Interested readers may refer to $[13,14]$ for detailed investigations of the effect of different weld profiles on the SCFs. In this local FE analysis, SCF values of the chord and braces are calculated by considering axial stress, IPB stress, and out-of-plane bending (OPB) stress in the brace, respectively. A uniform pressure of $1 \mathrm{ksi}$ is applied at the end of the brace to simulate the brace nominal stress when computing the SCF for axial brace stress $\mathrm{SCF}_{\mathrm{ax}}$, while an IPB moment resulting in $1 \mathrm{ksi}$ extreme fibre stress and an OPB moment resulting in $1 \mathrm{ksi}$ extreme fibre stress are applied to compute the SCFs for IPB brace stress and OPB brace stress, that is, $\mathrm{SCF}_{\mathrm{ipb}}$ and $\mathrm{SCF}_{\mathrm{opb}}$, respectively. Figures 2(b)-2(e) present stress contours (S3 average), respectively, for the chord and overlapping braces of the concerned two-planar overlapped KT-joint under axial loading of unit pressure and in-plane bending of unit moment on one of the upper diagonal braces. It can be observed that, due to the overlapping effect, stress concentration appears at crown locations of the other upper diagonal brace. On the other hand, carry-over effect has some influence on stress concentrations at crown locations of two horizontal braces (adjacent to the upper diagonal braces) but minimal influence on the lower diagonal braces.

2.3. A Bracket-Stiffened Overlapped KT-Joint. As the most highly loaded part of a jack-up leg structure is normally at the upper guide for the field transit condition [2], the concerned KT-joints corresponding to the upper guide level in preceding sections are most critical and expected to be fatigue-sensitive during transit. For jack-up leg structures, as the dominant loadings in the chord and braces of tubular joints are in the axial and IPB directions, the crown toe at the intersection of the chord and upper diagonal braces is of maximum stress concentration, as illustrated in Figures 2(b)-2(e). In order to reduce stress concentrations at the intersection area of the concerned KT-joints and improve the fatigue performance of jack-up leg structures, a novel bracket-stiffened two-planar overlapped KT-joint is proposed in this study, where two brackets are added between the upper diagonal and horizontal braces to alleviate the stress concentration at the crown location. The design drawing and finite element mesh of the bracket-stiffened KT-joint are provided in Figure 3.

Stress contours of the bracket-stiffened KT-joint are plotted in Figures 4(a)-4(f) for the chord and overlapping braces with brackets under axial, IPB, and OPB loadings, respectively. When comparing the results of Figures $4(a)-4(d)$ with those of Figures 2(b)-2(e), it is found that, due to the effect of added brackets, stress concentrations at the crown toe of the chord and upper diagonal brace are alleviated under both axial and IPB loadings. The bracket-stiffening effect is more significant for IPB loading case, which is due to the fact that the brackets are added in the same plane with the upper diagonal and horizontal braces. On the other hand, due to the addition of brackets, stress concentrations also occur at the bracket-to-brace intersections, such as the upper and lower bracket toes as indicated in Figure 4(b) for axial loading case and the upper bracket toe in Figure 4(d) for IPB loading case, and the resulting effect on the jack-up leg fatigue analysis will also be investigated. For OPB loading case as shown in Figures $4(\mathrm{e})-4(\mathrm{f})$, stress concentration occurs at the saddle points of the chord and brace with smaller magnitudes as compared to those of the crown locations under axial loading.

To have a comparison with the bracket-stiffening effect on the stress concentration at the crown location, the gap between the upper diagonal and horizontal braces is increased for the original KT-joint (no bracket) from 2 to 3 inches. Stress values for SCF calculation are extracted from nodes on central lines of the effective ranges on the chord and brace surfaces. As the OPB loading has a negligible effect on the stress concentration at the crown locations (see Figures 4(e) and 4(f)), and the tubular joints in jack-up leg structures are mainly subjected to axial and IPB loadings, $\mathrm{SCF}$ due to the OPB brace stress $\left(\mathrm{SCF}_{\mathrm{opb}}\right)$ is not calculated herein and will be neglected in the further study. Figure 5 shows SCF calculation zones with two extrapolation nodes (black and red dots) for the two-planar overlapped KT-joint under different loadings and design conditions, and the SCF results are summarized in Table 2. It is observed that as brace gap increases, $\mathrm{SCF}_{\mathrm{ax}}$ and $\mathrm{SCF}_{\mathrm{ipb}}$ at the crown toe of the chord reduce from 2.52 to 2.29 and from 0.85 to 0.52 , respectively. However, both $\mathrm{SCF}_{\mathrm{ax}}$ and $\mathrm{SCF}_{\mathrm{ipb}}$ at the crown toe of the brace increase slightly. As for the proposed bracket-stiffened $\mathrm{KT}$-joint, $\mathrm{SCF}_{\mathrm{ax}}$ and $\mathrm{SCF}_{\mathrm{ipb}}$ at the crown toe of the chord have significant reductions from 2.52 to 1.66 and from 0.85 
TABLE 1: Structural dimension and yield strength of the concerned KT-joint model.

\begin{tabular}{lcccc}
\hline Joint member & & Dimension (inch) & Yield strength (ksi) \\
\hline Chord & Outer diameter & Wall thickness & 216 & 100 \\
Upper diagonal brace & 14.4 & 2.25 & 125 & 65 \\
Horizontal brace & 9.625 & 1.25 & 110 & 65 \\
Lower diagonal brace & 9.625 & 1.25 & 116 & 65 \\
\hline
\end{tabular}

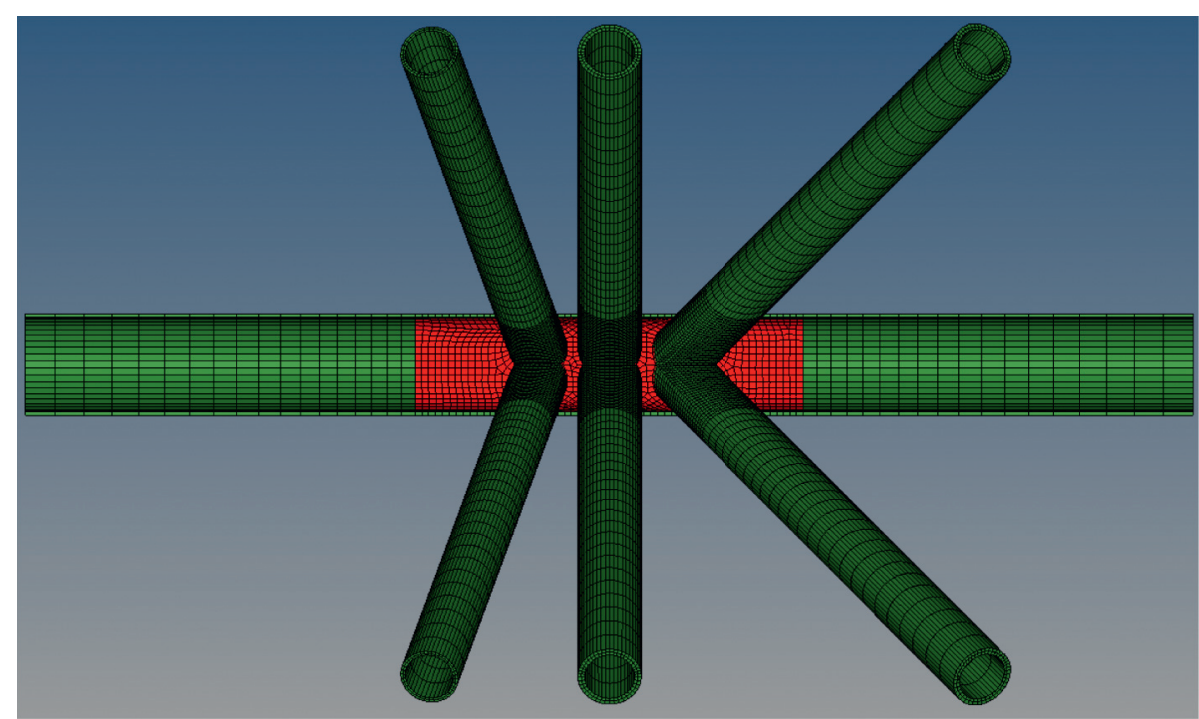

(a)

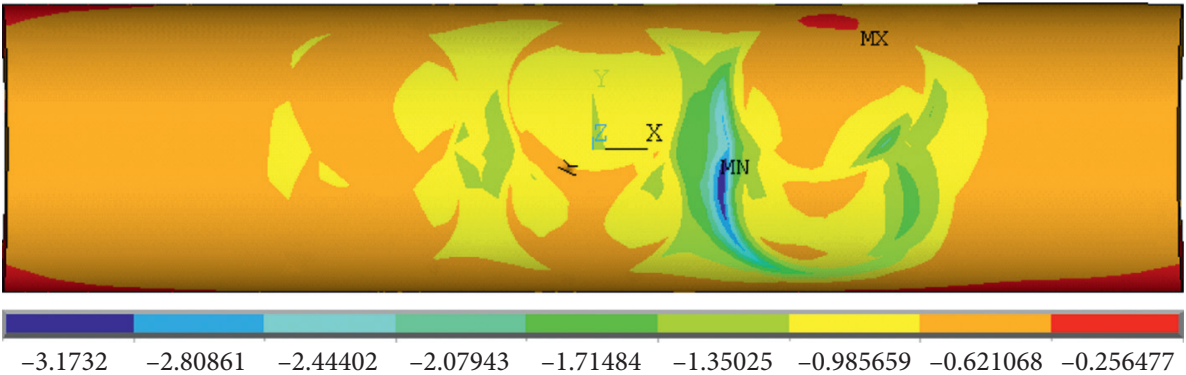

(b)

Figure 2: Continued. 


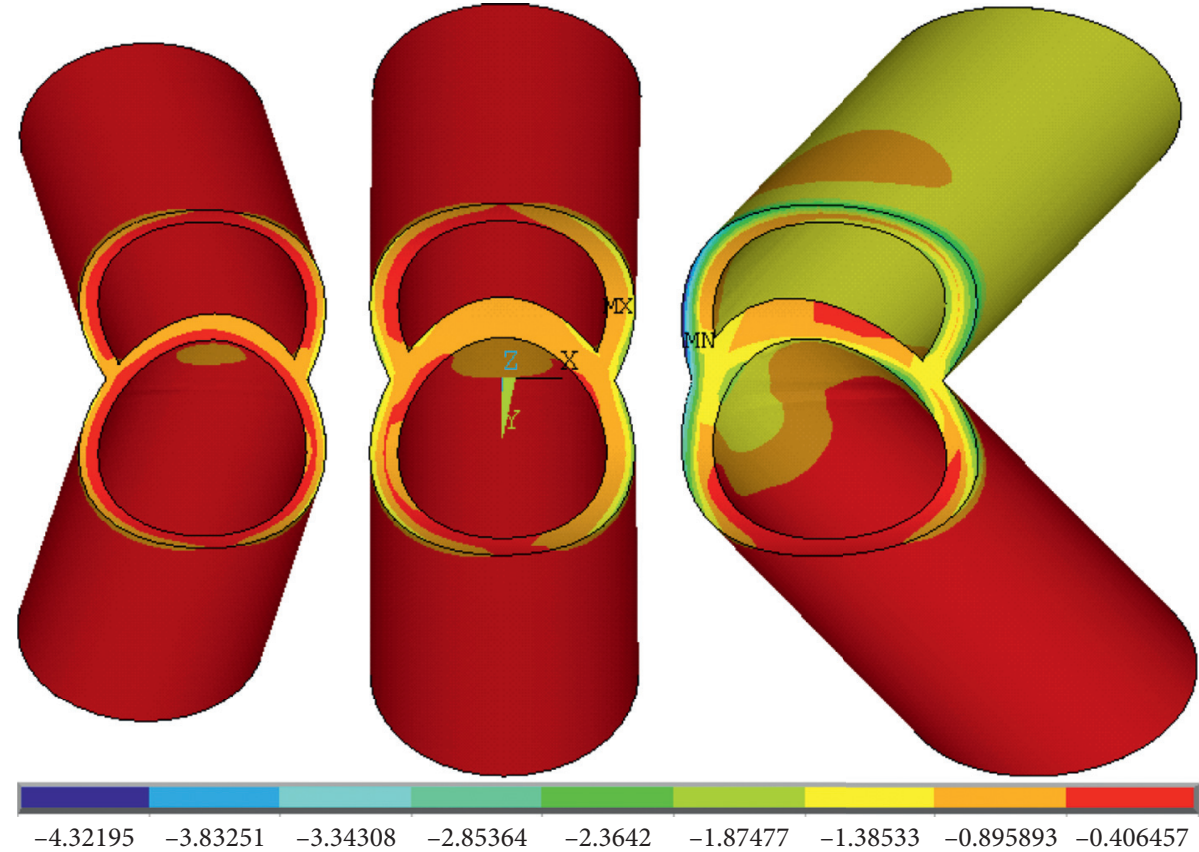

(c)
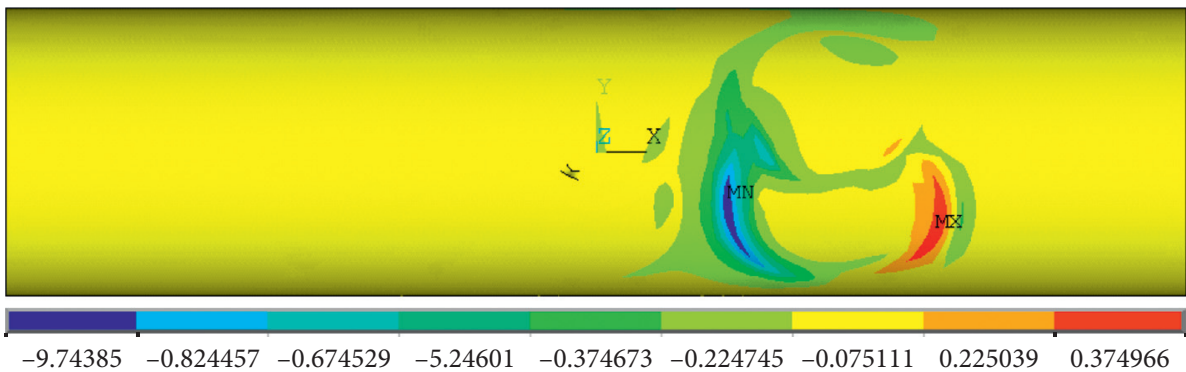

(d)
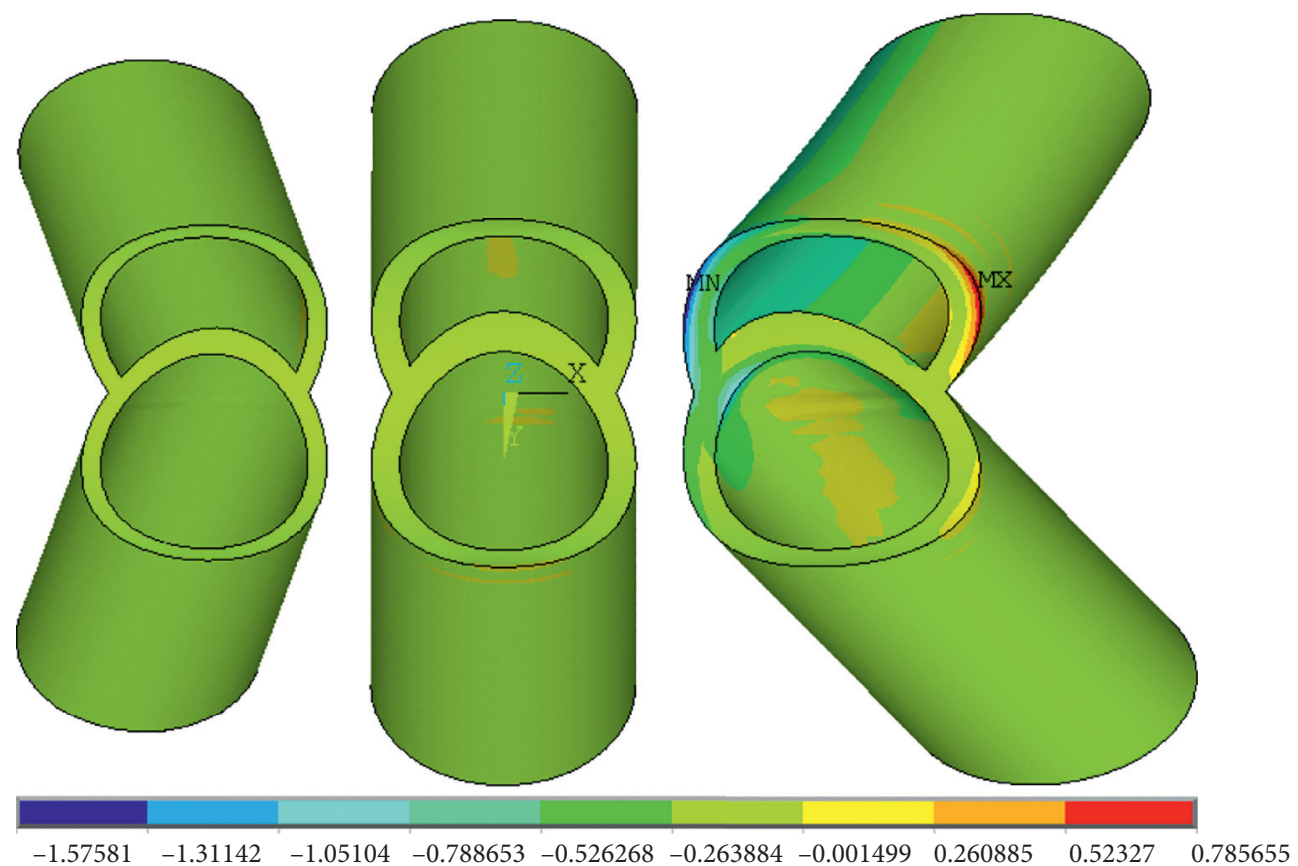

(e)

Figure 2: FE modeling of the two-planar overlapped KT-joint: (a) element mesh, stress contours of (b) the chord and (c) overlapping braces under axial loading of unit pressure, and stress contours of $(\mathrm{d})$ the chord and (e) overlapping braces under in-plane bending of unit moment. 


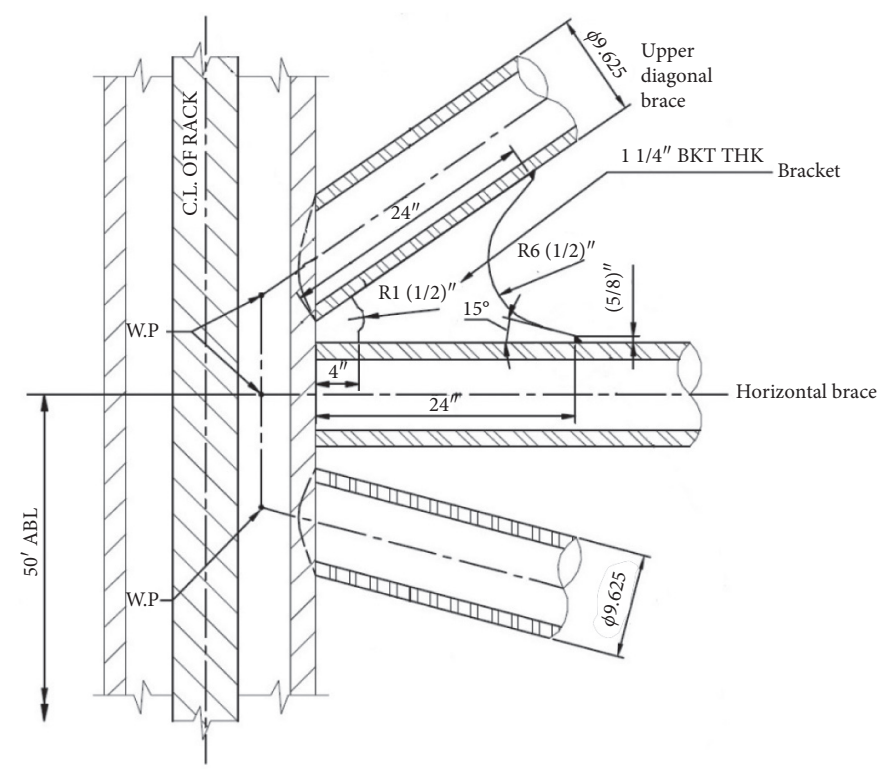

(a)

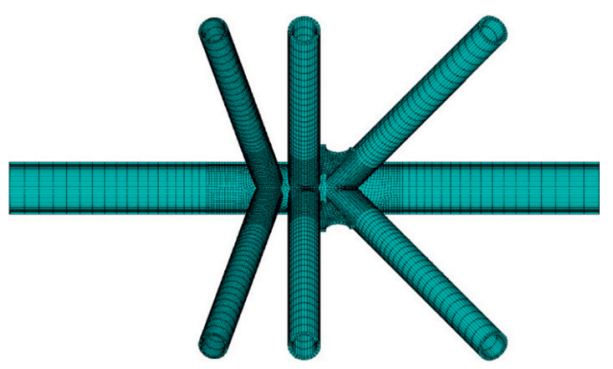

(b)

Figure 3: A bracket-stiffened two-planar overlapped KT-joint: (a) design drawing and (b) finite element mesh.

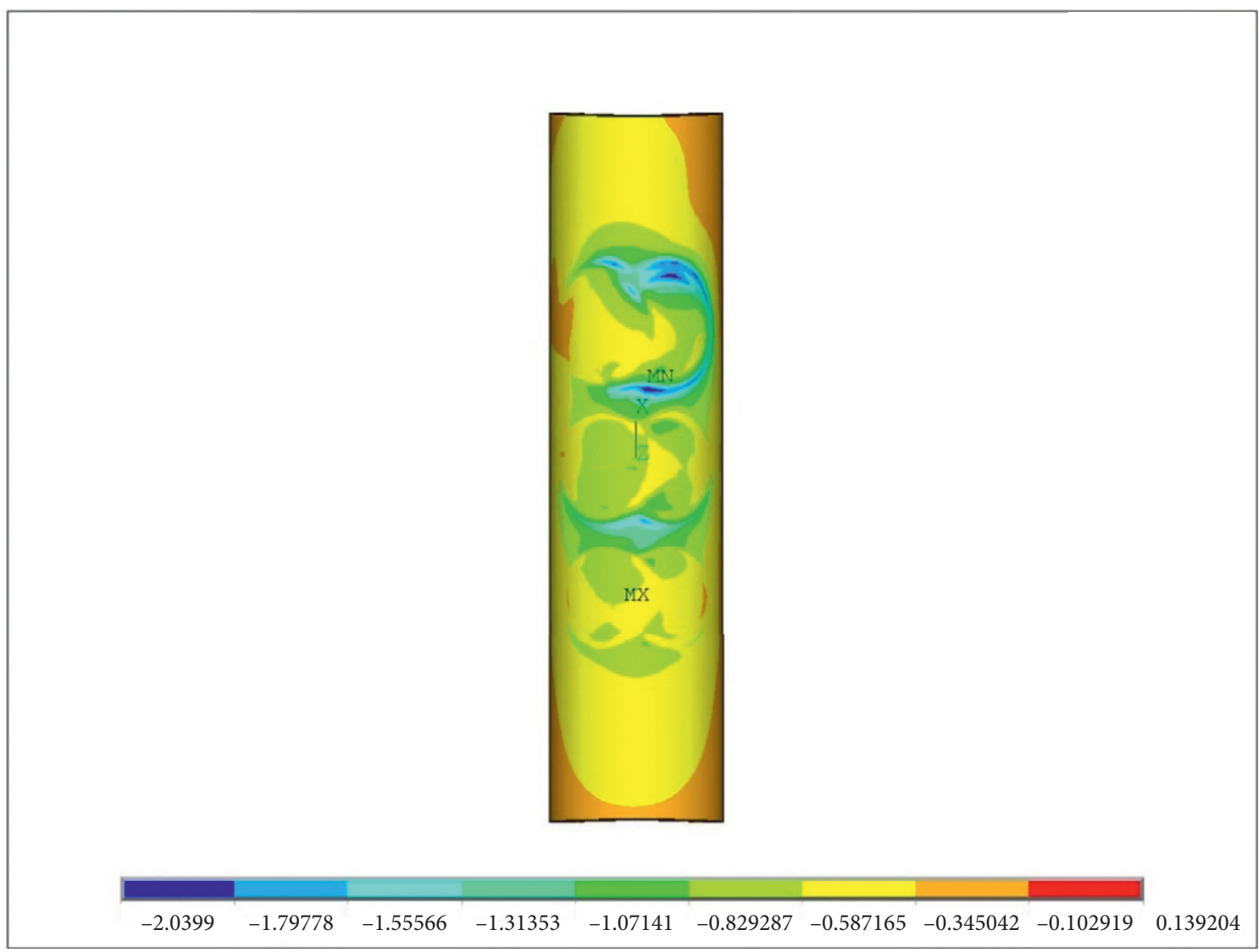

(a)

Figure 4: Continued. 


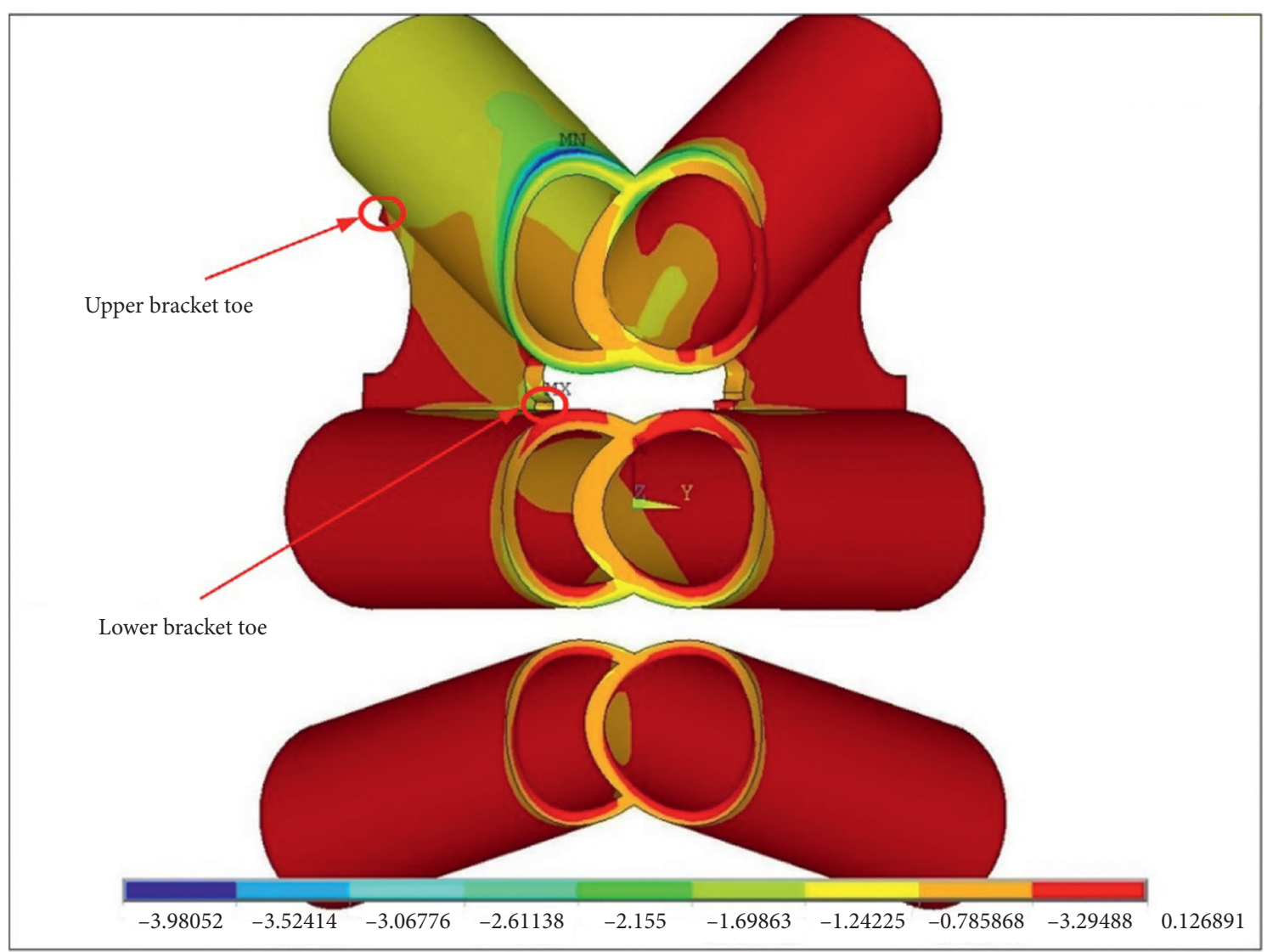

(b)

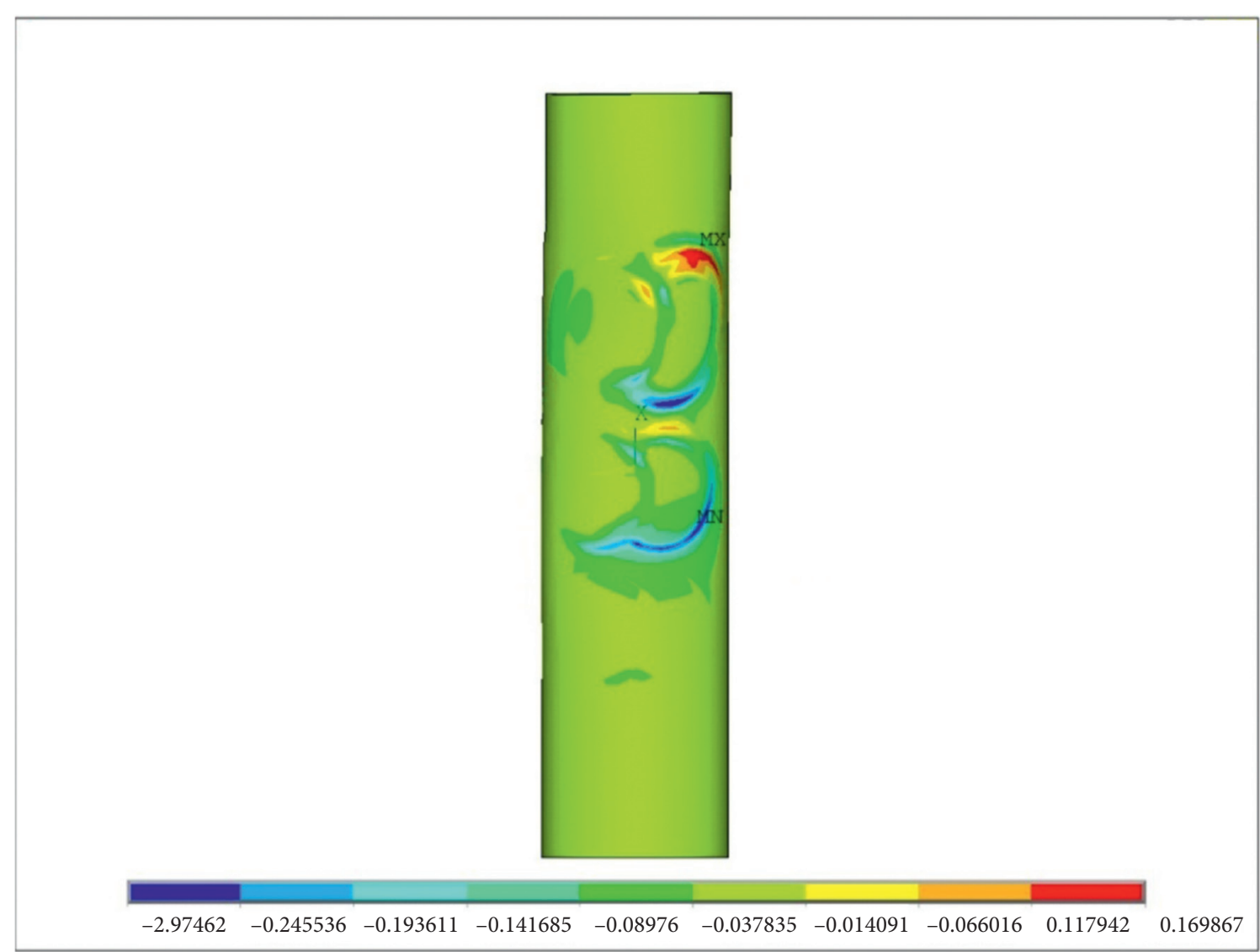

(c)

Figure 4: Continued. 


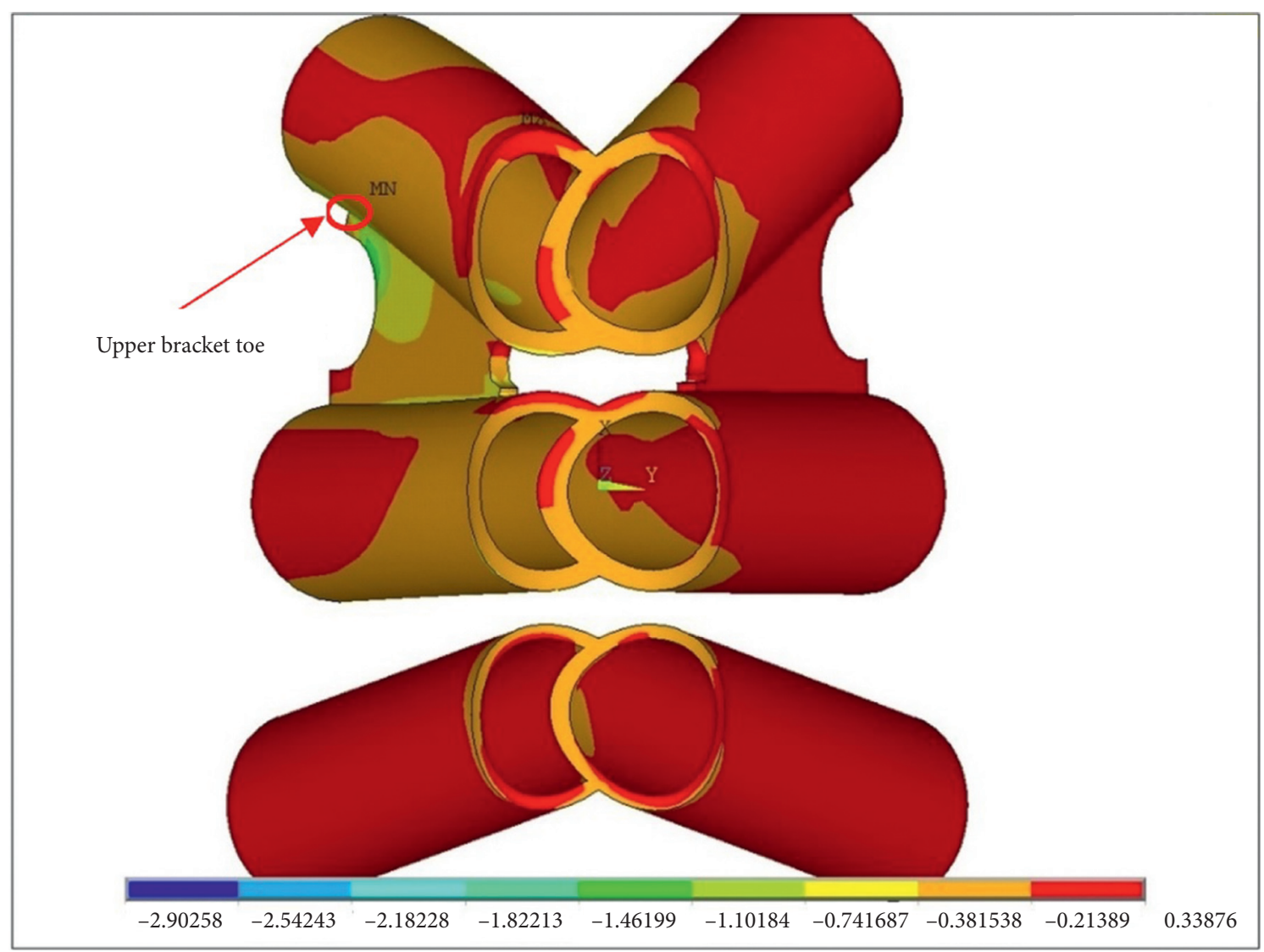

(d)

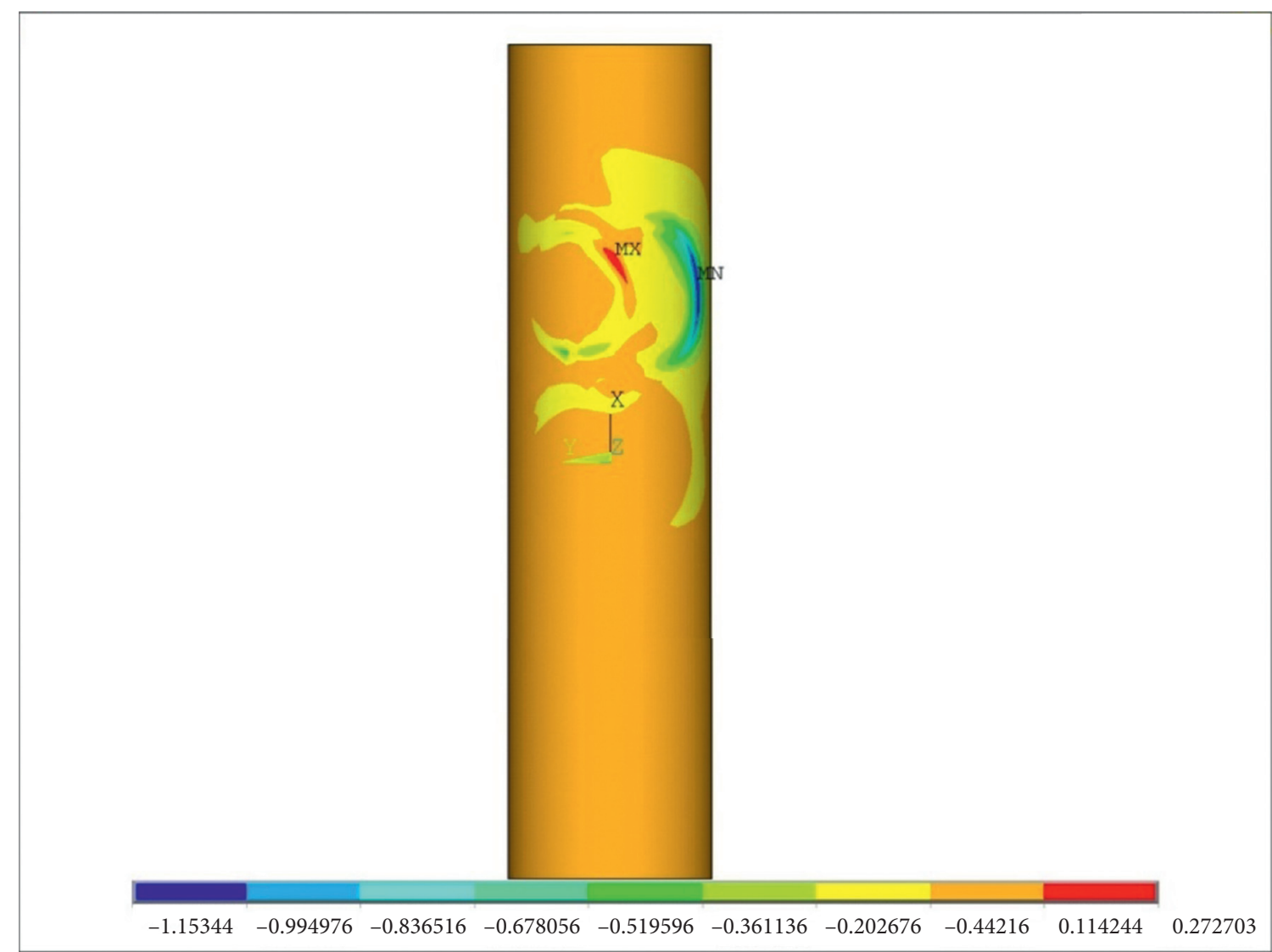

(e)

FIGURE 4: Continued. 


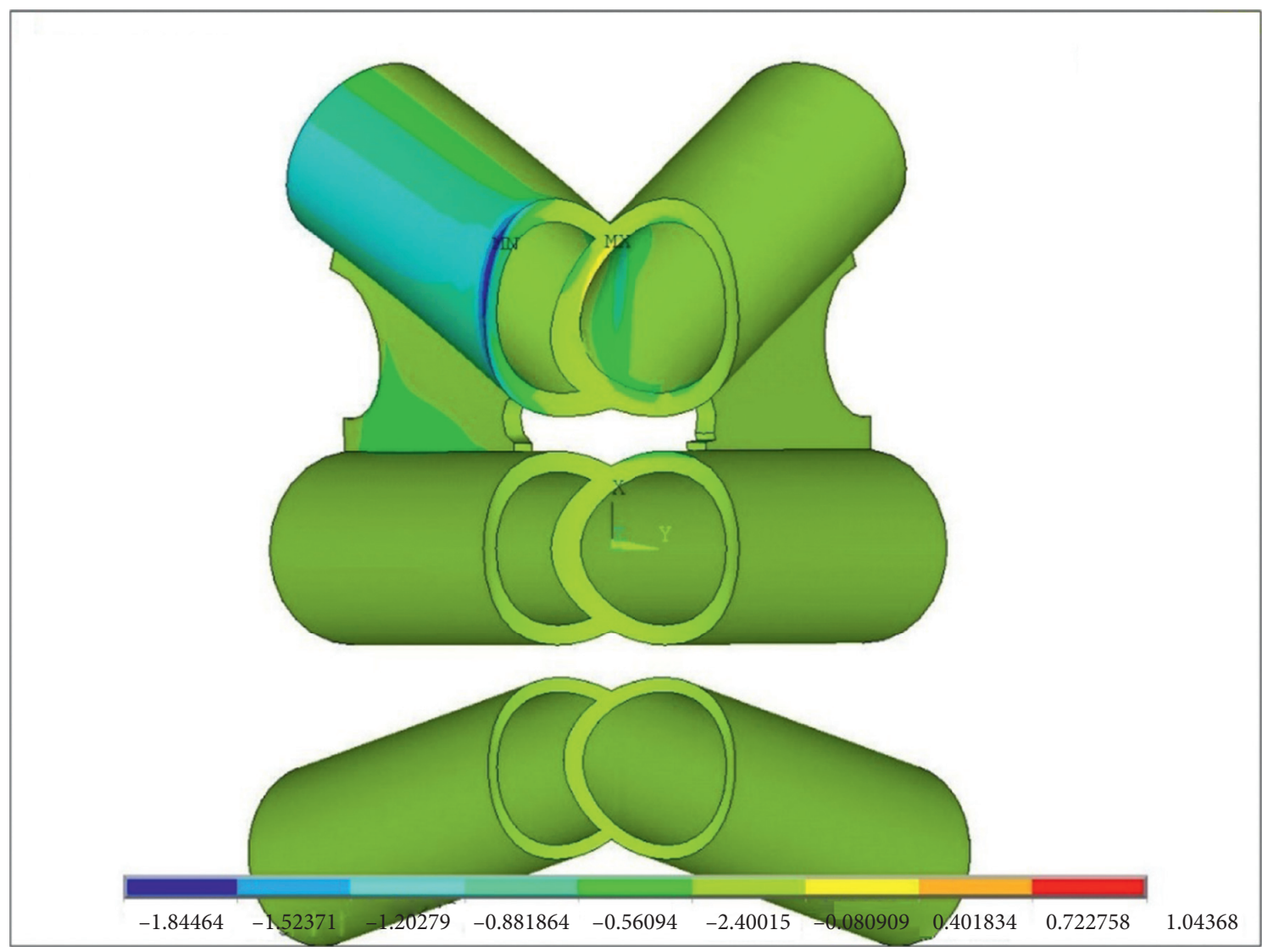

(f)

FiguRE 4: Stress contours of the bracket-stiffened two-planar overlapped KT-joint: (a) the chord and (b) overlapping braces with brackets under axial loading of unit pressure, (c) the chord and (d) overlapping braces with brackets under in-plane bending of unit moment, and (e) the chord and (f) overlapping braces with brackets under out-of-plane bending of unit moment.

to 0.08 , respectively. This enormous alleviation of stress concentration continues at the crown toe of the brace as $\mathrm{SCF}_{\mathrm{ax}}$ and $\mathrm{SCF}_{\mathrm{ipb}}$ reduce from 1.59 to 0.77 and from 0.62 to 0.22 , respectively. In addition, the SCF values for upper and lower bracket toes at the bracket-to-brace intersections under axial and IPB loadings are listed in Table 2 for further analysis.

It can be concluded from the preceding analysis that the proposed bracket-stiffened KT-joint outperforms the original KT-joint and KT-joint with larger brace gap in terms of the reduction of stress concentrations at the crown toes of the chord and braces for both axial and IPB loadings. Consequently, the superiority of the proposed bracketstiffened KT-joint will be further investigated for jack-up fatigue analysis in the following section.

\section{A Simplified Fatigue Analysis for Jack-Up in Field Transit Condition}

An offshore jack-up during field transit is normally considered to be wet-towed with leg fully elevated in a moderate sea environment [2]. To perform a simplified fatigue analysis, a hydrodynamic analysis for jack-up motion responses is first conducted under a significant wave height with different wave peak periods and wave incident angles. Then, the obtained 3-hour maximum motion responses and associated motion periods are applied to the global structural model of jack-up to compute the nominal stresses for the concerned KT-joints, which will be combined with the SCF results in Section 2 to obtain the hot spot stress ranges. Finally, the fatigue strength of the concerned KT-joint and fatigue life estimation of jack-up are computed according to the simplified fatigue assessment method in DNVGL-RP-C203 [40].

3.1. Jack-Up Motion Analysis. In this study, the jack-up unit has three triangular legs with longitudinal spacing of 129 feet, transverse spacing of 142 feet, and total leg length of 517 feet (including spudcan). The overall dimensions of the hull are $234 \times 208 \times 25$ (feet). The parameters for jack-up motion analysis are listed in Table 3 . The hydrodynamic analysis for jack-up motions is carried out using the diffraction-radiation program WAMIT [41]. Due to the geometric symmetry of the hull as shown in Figure 6, only half of the hull with wave incident angles from $0^{\circ}$ to $180^{\circ}$, that is, from the center line towards the starboard, needs to be modeled for hydrodynamic calculation. 

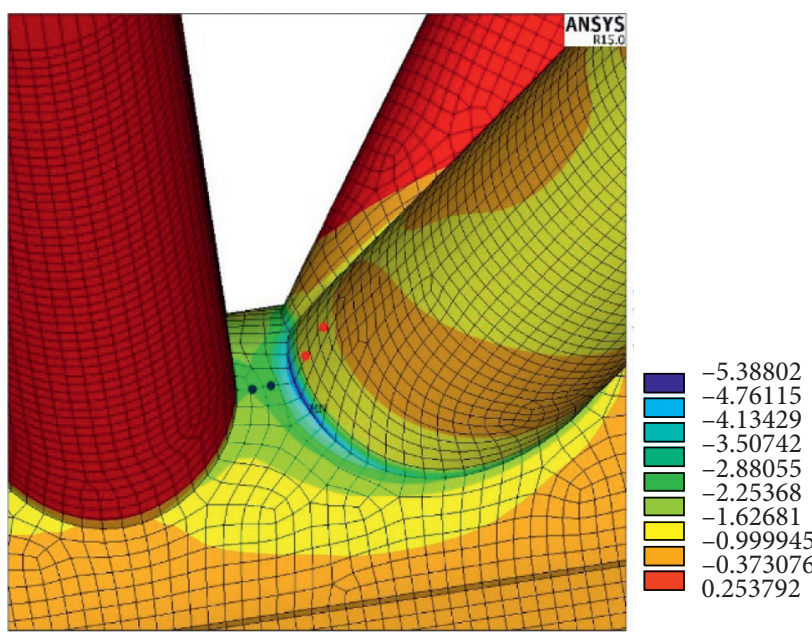

(a)

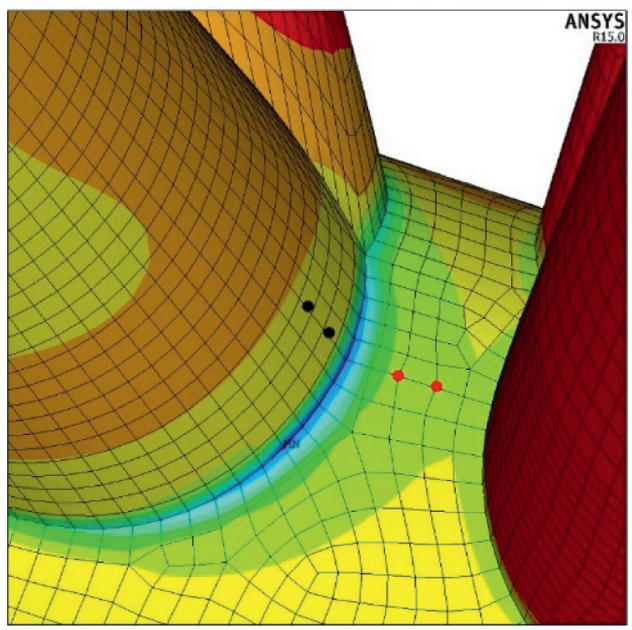

(c)

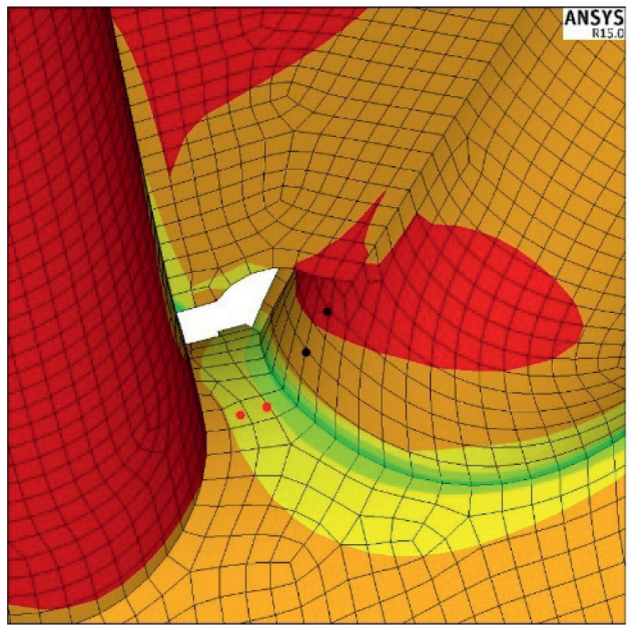

(e)

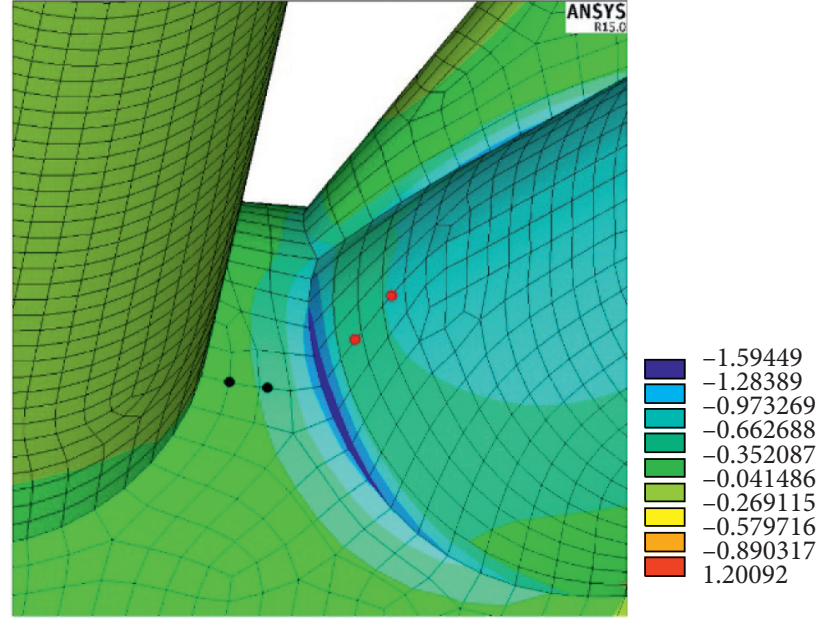

(b)

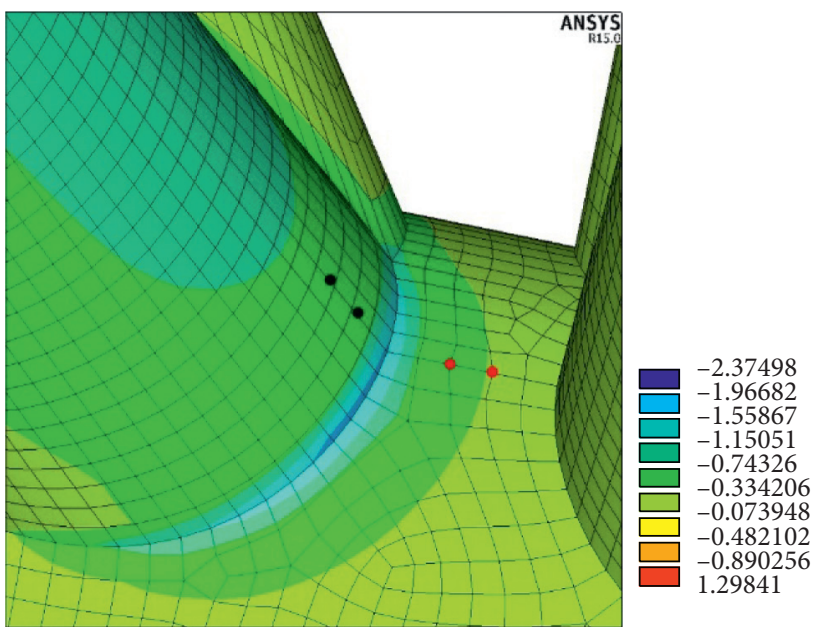

(d)

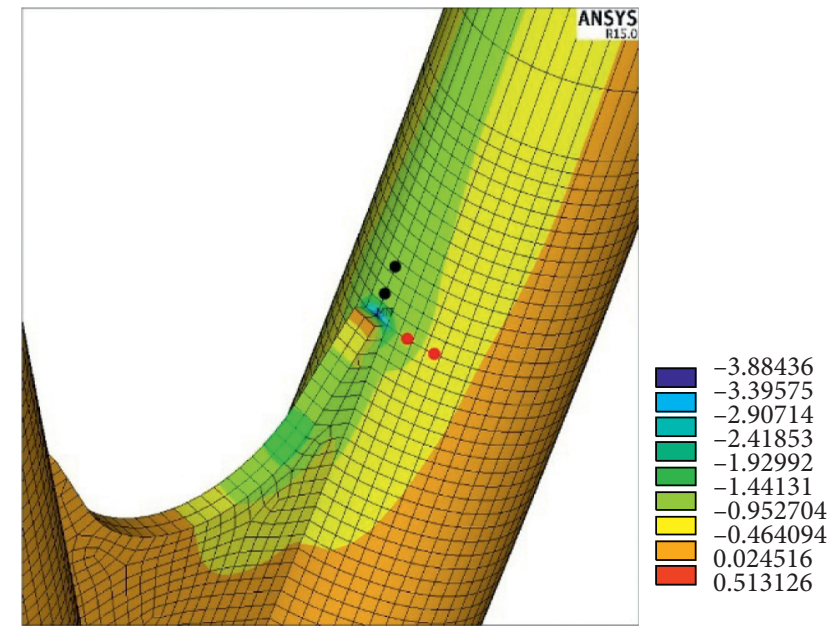

(f)

FIGURE 5: SCF calculation zones for the two-planar overlapped KT-joint: (a) axial and (b) IPB cases (2॥ brace gap without brackets), (c) axial and (d) IPB cases (3" brace gap without brackets), and (e) axial and (f) IPB cases (2 $/$ brace gap with brackets).

Response amplitude operators (RAOs) are calculated for 96 circular frequencies from 0.1 to $2 \mathrm{rad} / \mathrm{s}$ with an interval of $0.02 \mathrm{rad} / \mathrm{s}$ and 13 wave incident angles from $0^{\circ}$ to $180^{\circ}$ with an interval of $15^{\circ}$. The spectra of 6-DOF (i.e., surge, sway, heave, roll, pitch, and yaw) motion responses are established based on the RAOs and wave spectrum. The JONSWAP 
TABLE 2: SCF results for the two-planar overlapped KT-joint under different loadings and design conditions.

\begin{tabular}{|c|c|c|c|c|}
\hline \multirow[b]{2}{*}{ Loading } & \multirow[b]{2}{*}{ Location } & \multicolumn{3}{|c|}{ SCF values } \\
\hline & & $2 \prime \prime$ brace gap without brackets & $3 /$ brace gap without brackets & $\begin{array}{l}2 \prime \prime \text { brace gap } \\
\text { with brackets }\end{array}$ \\
\hline \multirow{4}{*}{ Axial } & Crown toe@ Chord & 2.52 & 2.29 & 1.66 \\
\hline & Crown toe@ Brace & 1.59 & 1.71 & 0.77 \\
\hline & Upper bracket toe @ Brace (longitudinal) & - & - & 1.38 \\
\hline & Lower bracket toe@ Brace (longitudinal) & - & - & 0.54 \\
\hline \multirow{4}{*}{$\begin{array}{l}\text { In-plane } \\
\text { bending }\end{array}$} & Crown toe@ Chord & 0.85 & 0.52 & 0.08 \\
\hline & Crown toe@Brace & 0.62 & 0.68 & 0.22 \\
\hline & Upper bracket toe@ Brace (longitudinal) & - & - & 1.40 \\
\hline & Upper bracket toe @ Brace (transverse) & - & - & 1.17 \\
\hline
\end{tabular}

TABle 3: Parameters for jack-up motion analysis.

\begin{tabular}{|c|c|}
\hline Parameter & Value \\
\hline Water depth & $400 \mathrm{ft} / 121.92 \mathrm{~m}$ \\
\hline Leg length & $517 \mathrm{ft} / 157.58 \mathrm{~m}$ \\
\hline Draft & $16.04 \mathrm{ft} / 4.89 \mathrm{~m}$ \\
\hline Displacement & $32184.9 \mathrm{kips} / 14598.8 \mathrm{MT}$ \\
\hline Longitudinal center of gravity (LCG) & $137.25 \mathrm{ft} / 41.83 \mathrm{~m}$ \\
\hline Transverse center of gravity (TCG) & $0.0 \mathrm{ft} / 0.0 \mathrm{~m}$ \\
\hline Vertical center of gravity (VCG) & $79.06 \mathrm{ft} / 24.10 \mathrm{~m}$ \\
\hline Moment of inertia $\left(I_{x x}\right)$ & $4.3915 E+08$ kips. $\mathrm{ft}^{2} / 1.8506 E+10 \mathrm{~kg} \mathrm{~m}^{2}$ \\
\hline Moment of inertia $\left(I_{y y}\right)$ & $4.7035 E+08$ kips.ft ${ }^{2} / 1.9821 E+10 \mathrm{~kg} \mathrm{~m}^{2}$ \\
\hline Moment of inertia $\left(I_{z z}\right)$ & $1.8198 E+08$ kips.ft ${ }^{2} / 7.6687 E+09 \mathrm{~kg} \mathrm{~m}^{2}$ \\
\hline
\end{tabular}

wave spectrum [42] is used with significant wave height $H_{s}=1.5 \mathrm{~m}$, peak enhancement factor $\gamma=3.3$, and wave peak period $T_{p}$ varying from 5 to $15 \mathrm{~s}$ with an interval of $0.5 \mathrm{~s}$. The corresponding zero-crossing period for random waves is $T_{z}=T_{p} / 1.286$. The standard deviation of response $\sigma$ is the square root of the integration of response spectrum over frequencies. The maximum response is then $\sigma(2 \ln N)^{1 / 2}$, where $N$ is the number of cycles for the response within a 3hour duration [43]. Due to the lack of environmental data for this fatigue study, a scatter diagram for the North Atlantic [44] is taken as a reference to select an appropriate $T_{z}$. Since fatigue damage is mostly associated with moderate seas, $T_{z}=7.5 \mathrm{~s}$ with the highest probability of occurrence is selected. Since $T_{p}$ varies from 5 to $15 \mathrm{~s}$ with an interval of $0.5 \mathrm{~s}$ and $T_{p}=1.286 T_{z}, T_{p}=9.5 \mathrm{~s}$ is finally obtained. Four wave incident angles, that is, $0^{\circ}, 30^{\circ}, 150^{\circ}$, and $180^{\circ}$, are considered in this fatigue analysis because these four wave headings have a higher probability to be experienced during the transit and are critical to the fatigue assessment. The 3hour maximum motion responses at $T_{p}=9.5 \mathrm{~s}$ and associated motion periods (the peak period of motion response spectrum) for four wave incident angles are presented in Table 4. This study does not account for the wind effect and jack-up forward speed. If jack-up forward speed is taken into account, the above-calculated motion responses tend to be smaller. In this regard, the results to be presented are on the conservative side.

3.2. Jack-Up Nominal Stress Analysis. Nominal stress refers to the stress at a cross section of the brace away from the hot spot, where fatigue crack initiation might occur. There is no geometric or weld profile effect of the structural detail on nominal stress. To compute the nominal stresses of the braces connected at the concerned KT-joints, a global finite element model of the jack-up leg structures in the field transit was generated in SACS [45], as shown in Figure 7. The legs are fully elevated and held in position with fixation systems, and all the pinions are disengaged. The structural members are mainly modeled by beam elements and the legto-hull connection behavior has been properly considered. The jack-cases are pinned at the hull main deck and bottom levels to serve as the boundary conditions. The inertial loads due to leg accelerations are automatically calculated by SACS (TOW module) based on the inputs of the motion center, motion angles, and periods. For each wave incident angle, the following eight combinations of roll/pitch with heave motion are examined for the legs to calculate the nominal stresses in the braces: positive pitch + positive heave, positive pitch + negative heave, negative pitch + positive heave, negative pitch + negative heave, positive roll + positive heave, positive roll + negative heave, negative roll + positive heave, and negative roll + negative heave.

As four wave incident angles $\left(0^{\circ}, 30^{\circ}, 150^{\circ}\right.$, and $\left.180^{\circ}\right)$ are considered in this fatigue analysis, the joint $\mathrm{B}$ of the starboard (STBD) leg is less critical compared to joints A and C of the same leg (see Figure 6). The port (PORT) leg mirrors the starboard leg, and thus the results of both legs will be the same. Moreover, the results of joints B and $\mathrm{C}$ of the forward (FWD) leg are the same due to the symmetry. Therefore, nominal stress ranges of the upper diagonal braces at joints 


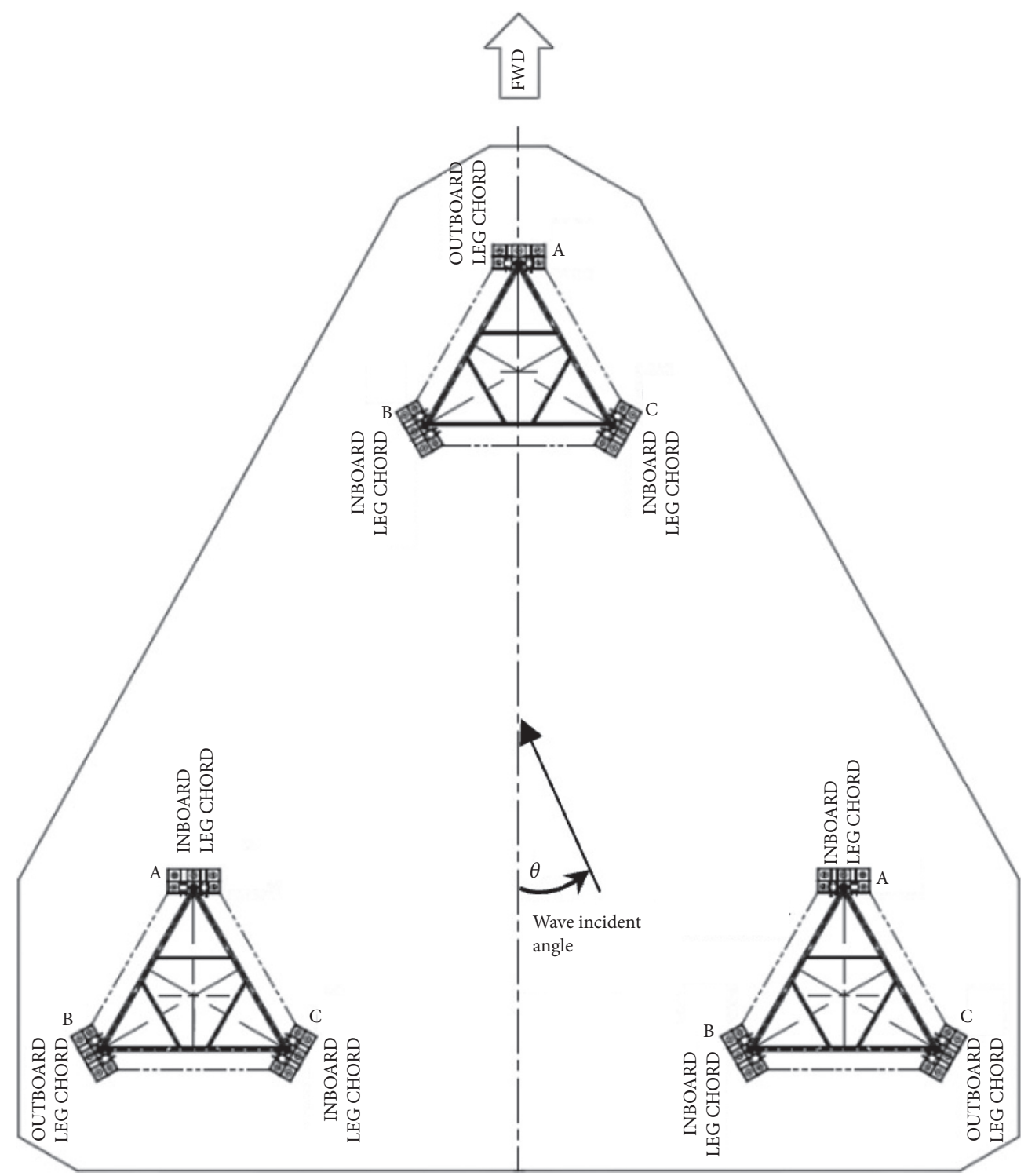

Figure 6: Schematic top view of the hull and leg structures with concerned KT-joints.

$\mathrm{A}$ and $\mathrm{C}$ of the forward and starboard legs in Figure 6 are computed for the fatigue assessment. Table 5 lists the nominal stress ranges of axial stress $\Delta f_{\mathrm{ax}}$, IPB stress $\Delta f_{\mathrm{ipb}}$, and OPB stress $\Delta f_{\mathrm{opb}}$ of the upper diagonal braces at the selected joints. It is obvious that axial and IPB stresses are more significant than OPB stress. As the crown toes at the joint intersection of the chord and upper diagonal braces are concerned with maximum stress concentration that is not affected by out-of-plane bending but axial loading and inplane bending as demonstrated in Figure 4, only nominal stress ranges of axial stress $\Delta f_{\mathrm{ax}}$ and IPB stress $\Delta f_{\mathrm{ipb}}$ are considered in the following fatigue analysis.

3.3. Fatigue Strength Evaluation of the KT-Joints. For practical applications, the result of fatigue strength is usually presented in terms of accumulated damage or fatigue life. It is assumed in this simplified fatigue analysis that the long- term distribution of stress range is represented by a twoparameter Weibull distribution $[2,40]$ :

$$
Q(\Delta \sigma)=\exp \left[-\left(\frac{\Delta \sigma}{\delta}\right)^{h}\right]
$$

where $Q$ is the probability for exceedance of the stress range $\Delta \sigma, h$ is Weibull shape parameter, and $\delta$ is Weibull scale parameter with the definition of

$$
\delta=\frac{\Delta \sigma_{0}}{\left(\ln N_{0}\right)^{1 / h}}
$$

where $N_{0}$ is the number of cycles in a referenced period and $\Delta \sigma_{0}$ is the largest stress range out of $N_{0}$ cycles. The accumulated fatigue damage is then given by

$$
D=\frac{N_{T} \delta^{m}}{\bar{a}} \Gamma\left(\frac{m}{h}+1\right)
$$


TABLE 4: Maximum motion responses at $T_{p}=9.5 \mathrm{~s}$ and associated motion periods for different wave incident angles.

\begin{tabular}{lcccc}
\hline Jack-up motion & $0^{\circ}$ & $30^{\circ}$ & $150^{\circ}$ & $180^{\circ}$ \\
\hline Heave $(m) /$ period (s) & $0.99 / 9.52$ & $1.01 / 9.52$ & $1.03 / 9.52$ & $0.97 / 9.52$ \\
Roll (deg)/period (s) & $0.00 / 9.82$ & $0.38 / 9.82$ & $0.35 / 9.82$ & $0.00 / 9.82$ \\
Pitch (deg)/period (s) & $2.43 / 12.56$ & $2.09 / 12.56$ & $2.13 / 12.56$ & $2.51 / 12.56$ \\
\hline
\end{tabular}

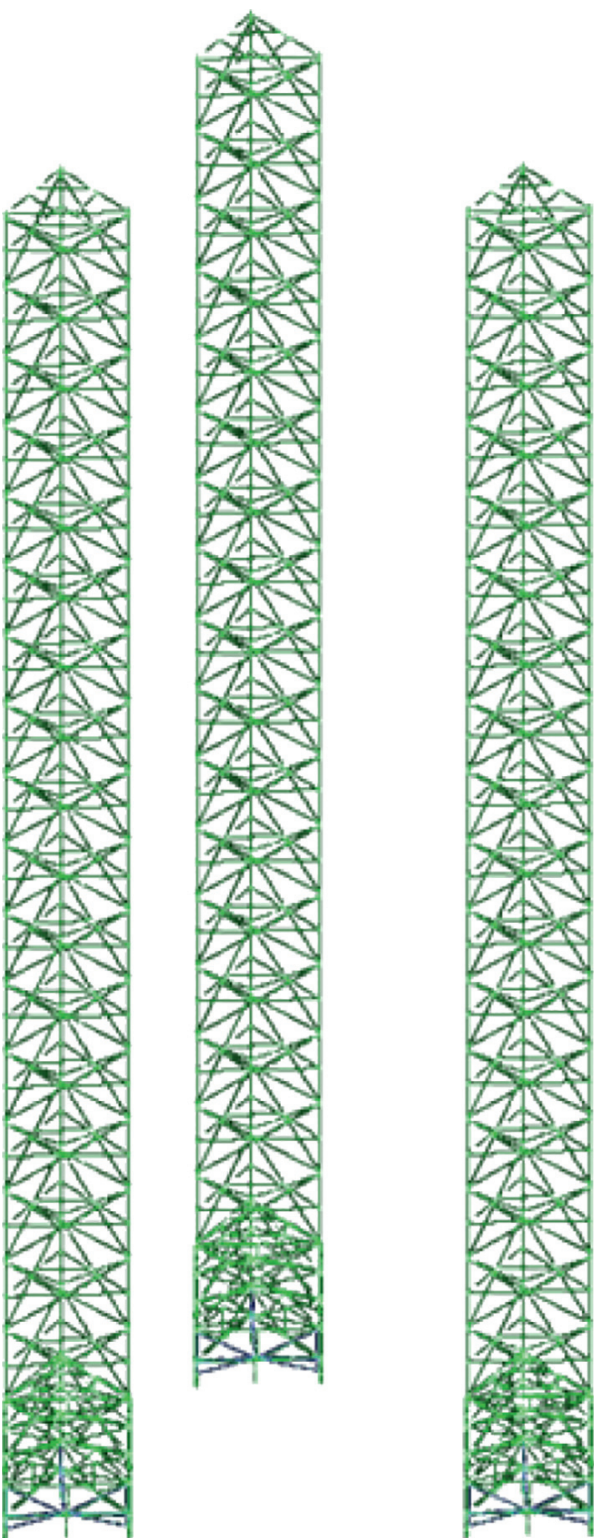

Figure 7: A global finite element model of the jack-up leg structures in field transit.

where $\Gamma$ is the gamma function, $N_{T}$ is the number of cycles in the design life, $\bar{a}$ is the coefficient, and $m$ is the inverse slope of the S-N curve. Since $N_{T}, \bar{a}, h$, and $m$ are constant, fatigue damage $D$ can be simply expressed as

$$
D \propto\left(\Delta \sigma_{0}\right)^{m}
$$

where $\sigma_{0}$ is the hot spot stress for the chord and brace, and the nominal stress for the bracket.
According to the nominal stress analysis in Section 3.2, among the stresses, the axial and IPB components possess around $75 \%$ and $25 \%$, respectively, for the most critical joints, that is, joints A @ FWD Leg and A @ STBD Leg. For easy comparison, the fatigue damage at the crown toe of the chord for the original KT-joint of $2 /$ brace gap without brackets is taken as 1 , and the other counterparts are presented as the relative values. Estimation of the bracket nominal stress is somewhat difficult due to the various stress gradients as shown in Figure 5(f). The details of stress level at the upper bracket-to-brace connection are shown in Figure 8. The values of 0.81 (axial) and 1.1 (IPB) are taken as the bracket nominal stresses conservatively. Since stress concentration at the upper bracket toe is more significant than that at the lower bracket toe (see Table 2), fatigue damage at the lower bracket toe is not calculated. Comparison of fatigue damages for the overlapped KT-joints under different design conditions is presented in Table 6. From the results, it is found that (1) for brace gap increasing from $2 /$ to $3 \prime \prime$, the fatigue damage at the crown toe of the chord decreases from 1 to 0.68 . However, the fatigue damage at the crown toe of the brace slightly increases. As the $2 /$ brace gap is too small for SCF calculation, the second point for stress extrapolation defined by DNV code [40] is not available. To be conservative, a position nearer to the weld toe is chosen, which results in larger SCF values for the crown toe of the chord. In this regard, the effect of larger brace gap on the improvement of fatigue performance is not much. (2) Due to the addition of the bracket, the fatigue damages at the crown toes of the chord and brace reduce from 1 to 0.22 and from 0.22 to 0.02 , respectively. On the other hand, the computed relative damages at the upper bracket toes of the brace and bracket are 0.56 and 0.57 , respectively. (3) In summary, the proposed bracket-stiffened KT-joint outperforms the original KTjoint and KT-joint with larger brace gap in terms of fatigue strength.

3.4. Fatigue Life Prediction of Jack-Up in Field Transit Condition. Due to the superior fatigue performance, the proposed bracket-stiffened KT-joint is used to predict the fatigue life of jack-up in field transit condition. According to the industrial guidelines $[2,40]$, hot spot stress range (HSSR) is obtained by multiplying the nominal stress with appropriate SCF. The hot spot stresses at the crown points (chord and brace) of the proposed KT-joint are given by

$$
\begin{aligned}
& \mathrm{HSS}_{\text {chord }}=\mathrm{SCF}_{\mathrm{ax}-\mathrm{ch}} \cdot f_{\mathrm{ax}} \pm \mathrm{SCF}_{\mathrm{ipb}-\mathrm{ch}} \cdot f_{\mathrm{ipb}}, \\
& \mathrm{HSS}_{\mathrm{brace}}=\mathrm{SCF}_{\mathrm{ax}-\mathrm{br}} \cdot f_{\mathrm{ax}} \pm \mathrm{SCF}_{\mathrm{ipb}-\mathrm{br}} \cdot f_{\mathrm{ipb}},
\end{aligned}
$$

where $f_{\mathrm{ax}}$ and $f_{\mathrm{ipb}}$ are nominal axial and IPB stresses in the brace, respectively, $\mathrm{SCF}_{\mathrm{ax}-\mathrm{ch}}$ and $\mathrm{SCF}_{\mathrm{ipb}-\mathrm{ch}}$ are chord SCFs 
TABLE 5: Nominal stress ranges (ksi) of upper diagonal braces at the selected KT-joints.

\begin{tabular}{lcccccccccccc}
\hline \multirow{2}{*}{ Wave heading } & \multicolumn{3}{c}{ A @ FWD Leg } & \multicolumn{3}{c}{ C @ FWD Leg } & \multicolumn{3}{c}{ A @ STBD Leg } & \multicolumn{3}{c}{ C @ STBD Leg } \\
& $\Delta f_{\mathrm{ax}}$ & $\Delta f_{\mathrm{ipb}}$ & $\Delta f_{\mathrm{opb}}$ & $\Delta f_{\mathrm{ax}}$ & $\Delta f_{\mathrm{ipb}}$ & $\Delta f_{\mathrm{opb}}$ & $\Delta f_{\mathrm{ax}}$ & $\Delta f_{\mathrm{ipb}}$ & $\Delta f_{\mathrm{opb}}$ & $\Delta f_{\mathrm{ax}}$ & $\Delta f_{\mathrm{ipb}}$ & $\Delta f_{\mathrm{opb}}$ \\
\hline $0^{\circ}$ & 5.72 & 2.14 & 0.08 & 5.44 & 0.70 & 0.73 & 5.65 & 1.94 & 0.11 & 5.45 & 0.74 \\
$30^{\circ}$ & 5.60 & 1.94 & 0.25 & 5.45 & 1.04 & 0.71 & 5.52 & 1.80 & 0.27 & 5.46 & 1.08 & 0.75 \\
$150^{\circ}$ & 5.64 & 1.96 & 0.23 & 5.48 & 1.02 & 0.71 & 5.56 & 1.82 & 0.25 & 5.48 & 1.06 & 0.72 \\
$180^{\circ}$ & 5.90 & 2.20 & 0.09 & 5.62 & 0.72 & 0.77 & 5.84 & 2.00 & 0.11 & 5.62 & 0.76 & 0.77 \\
\hline
\end{tabular}

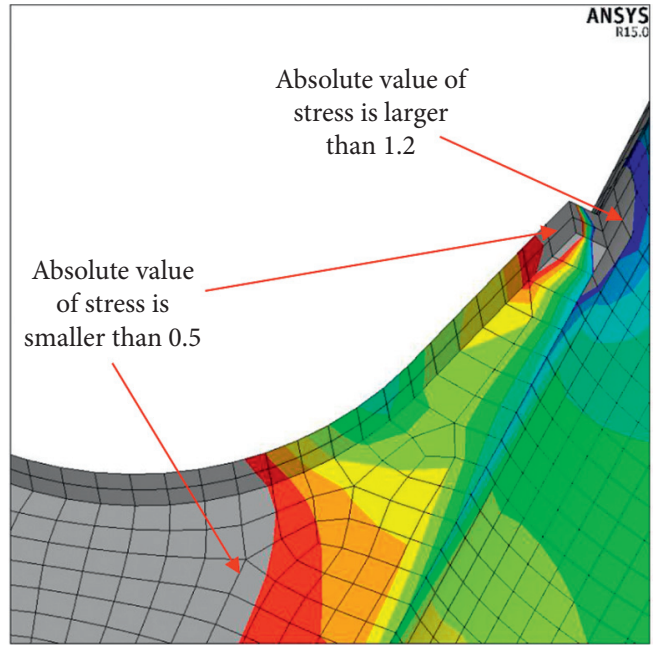

(a)

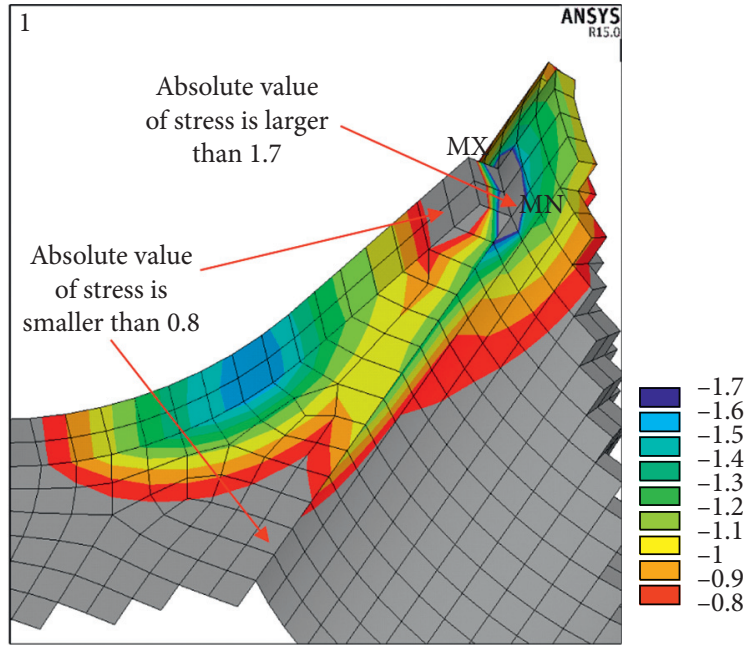

(b)

Figure 8: Details of stress level at the upper bracket-to-brace connection under: (a) axial loading and (b) IPB loading.

TABLE 6: Comparison of fatigue damage for the KT-joints under different design conditions.

\begin{tabular}{|c|c|c|c|c|c|c|c|}
\hline Design condition & Location & Axial stress & IPB stress & Stress & S-N curve & Damage & Relative damage \\
\hline \multirow{2}{*}{$2^{\prime \prime}$ brace gap without brackets } & Crown toe @ Chord & 2.52 & 0.85 & 2.10 & $\mathrm{~T}$ & $3.242 \times 10^{-9}$ & 1.00 \\
\hline & Crown toe@Brace & 1.59 & 0.62 & 1.35 & $\mathrm{~T}$ & $7.160 \times 10^{-9}$ & 0.22 \\
\hline \multirow{2}{*}{$3^{\prime \prime}$ brace gap without brackets } & Crown toe@Chord & 2.29 & 0.52 & 1.85 & $\mathrm{~T}$ & $2.200 \times 10^{-9}$ & 0.68 \\
\hline & Crown toe@Brace & 1.71 & 0.68 & 1.45 & $\mathrm{~T}$ & $0.897 \times 10^{-9}$ & 0.28 \\
\hline \multirow{4}{*}{$2^{\prime \prime}$ brace gap with brackets } & Crown toe@ Chord & 1.66 & 0.08 & 1.27 & $\mathrm{~T}$ & $7.062 \times 10^{-10}$ & 0.22 \\
\hline & Crown toe@Brace & 0.77 & 0.22 & 0.63 & $\mathrm{~T}$ & $7.406 \times 10^{-11}$ & 0.02 \\
\hline & Upper bracket toe@Brace & 1.38 & 1.40 & 1.39 & $\mathrm{~F}$ & $1.816 \times 10^{-9}$ & 0.56 \\
\hline & Upper bracket toe @ Bracket & 0.81 & 1.10 & 0.88 & $\mathrm{~W}$ & $1.835 \times 10^{-9}$ & 0.57 \\
\hline
\end{tabular}

Note. (1) Axial stress is the axial SCF value when $1 \mathrm{ksi}$ uniform pressure is applied on the end of brace, and IPB stress is the IPB SCF value with an IPB moment resulting in $1 \mathrm{ksi}$ extreme fibre stress applied. (2) Stress $=0.75^{*}$ axial stress $+0.25^{*}$ IPB stress.

due to axial and IPB stresses, respectively, and $\mathrm{SCF}_{\mathrm{ax}-\mathrm{br}}$ and $\mathrm{SCF}_{\mathrm{ipb}-\mathrm{br}}$ are brace SCFs due to axial and IPB stresses, respectively. To be conservative, the maximum SCF values of chord and brace in Table 2 (last column) are used for both axial and IPB cases; that is, $\mathrm{SCF}_{\mathrm{ax}-\mathrm{ch}}=\mathrm{SCF}_{\mathrm{ipb}-\mathrm{ch}}=1.66$ and $\mathrm{SCF}_{\mathrm{ax}-\mathrm{br}}=\mathrm{SCF}_{\mathrm{ipb}-\mathrm{br}}=1.40$. The hot spot stress ranges at the crown points of the proposed KT-joints are presented in Table 7.

Assume equal probability of the $n_{w}=4$ wave incident angles $\theta_{i} \quad\left(0^{\circ}, 30^{\circ}, 150^{\circ}\right.$, and $\left.180^{\circ}\right)$; that is, $p\left(\theta_{i}\right)=\left(1 / n_{w}\right), i=1, \ldots, n_{w}$. The fatigue damage $D$ in equation (3) can be rewritten as

$$
D=\frac{N_{T}}{\bar{a}} \sum_{i=1, \ldots, n_{w}} p\left(\theta_{i}\right)\left[\frac{\Delta \sigma_{0}^{i}}{\left(\ln N_{0}^{i}\right)^{1 / h_{i}}}\right]^{m} \Gamma\left(\frac{m}{h_{i}}+1\right),
$$

where $h_{i}$ is conservatively assumed to be 1.1 and $N_{0}^{i}=1000$ for all wave incident angles. The fatigue check is based on the expression:

$$
D \leq \frac{1.0}{\mathrm{FDF}}
$$

where a fatigue design factor (FDF) of 1.0 is typically employed for the fatigue assessment of MODU according to ABS FAOS [46]. This gives the fatigue life $N_{T}$ (in cycles):

$$
N_{T}=\frac{\bar{a}}{\mathrm{FDF}} \cdot \frac{1}{\sum_{i=1, \ldots, n_{w}} p\left(\theta_{i}\right)\left[\Delta \sigma_{0}^{i} /\left(\ln N_{0}^{i}\right)^{1 / h_{i}}\right]^{m} \Gamma\left(\left(m / h_{i}\right)+1\right)} .
$$


TABLE 7: Hot spot stress ranges (ksi) at the crown points of the proposed KT-joints.

\begin{tabular}{lcccccccc}
\hline \multirow{2}{*}{ Wave heading } & \multicolumn{2}{c}{ A @ FWD Leg } & \multicolumn{2}{c}{ C @ FWD Leg } & \multicolumn{2}{c}{ A @ STBD Leg } & \multicolumn{2}{c}{ C @ STBD Leg } \\
& Chord & Brace & Chord & Brace & Chord & Brace & Chord & Brace \\
\hline $0^{\circ}$ & 14.74 & 12.38 & 11.51 & 9.67 & 14.23 & 11.95 & 11.61 \\
$30^{\circ}$ & 14.14 & 11.88 & 12.17 & 10.22 & 13.73 & 11.53 & 12.26 \\
$150^{\circ}$ & 14.25 & 11.97 & 12.19 & 10.24 & 13.84 & 11.62 & 12.26 \\
$180^{\circ}$ & 15.19 & 12.76 & 11.89 & 9.99 & 14.70 & 12.35 & 11.96 \\
\hline
\end{tabular}

TABle 8: Fatigue life (years) at the concerned crown points of the proposed KT-joints.

\begin{tabular}{lcccccccc}
\hline \multirow{2}{*}{ Proposed KT-joints } & \multicolumn{2}{c}{ A @ FWD Leg } & \multicolumn{2}{c}{ C @ FWD Leg } & \multicolumn{2}{c}{ A @ STBD Leg } & \multicolumn{2}{c}{ C @ STBD Leg } \\
& Chord & Brace & Chord & Brace & Chord & Brace & Chord & Brace \\
\hline Fatigue life & 18.6 & 48.2 & 26.1 & 83.9 & 16.5 & 52.9 & 29.3 & 82.2 \\
\hline
\end{tabular}

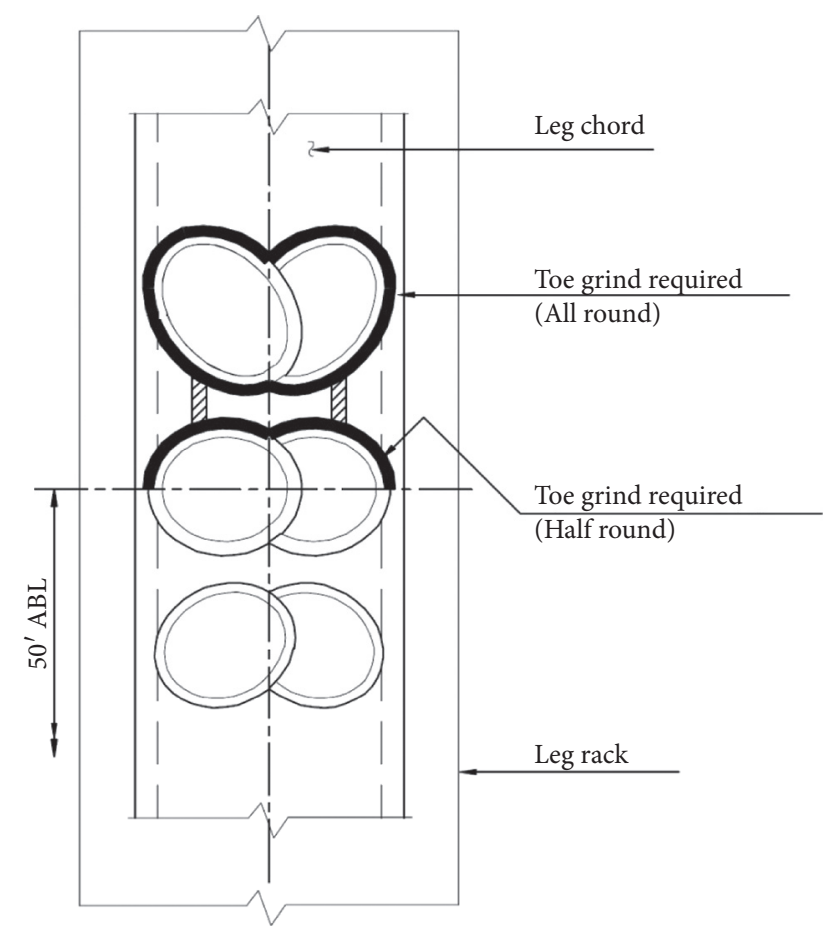

Figure 9: Recommended grinding of weld toe for the proposed KT-joint.

Fatigue life estimation at the concerned crown points of the proposed bracket-stiffened KT-joint is listed in Table 8. The crown point of joint A @ STBD Leg has the shortest fatigue life of 16.5 years, followed by joint A @ FWD Leg with fatigue life of 18.6 years.

Fatigue life of a certain joint indicates the total towing period that can be experienced by the jack-up until fatigue damage happens to this particular joint. The towing condition is assumed to be under a sea state with $H_{s}=1.5 \mathrm{~m}$ all the time, which reflects the conservatism in this fatigue study because the jack-up may also be towed in sea states with smaller $H_{s}$ in practice. Due to a number of conservative assumptions in this study, the actual fatigue life is expected to be longer than the estimated fatigue life. According to ABS Commentary on FAOS [47], grinding is an efficient method for reliable fatigue life improvement after fabrication. Increase of fatigue life by a factor of 2.2 can be achieved with grinding. The recommended grinding of weld toe for the proposed KT-joint is illustrated in Figure 9.

\section{Conclusions}

This paper presents a novel bracket-stiffened two-planar overlapped tubular KT-joint for offshore jack-up fatigue analysis in the field transit condition. By local finite element analysis, two-planar overlapped KT-joints are first investigated under different loading conditions (axial, IPB, and OPB) and compared among three design scenarios (the original KT-joint with $2^{\prime \prime}$ brace gap, the KT-joint with 3" brace gap, and the proposed bracket-stiffened KT-joint). As the KT-joints corresponding to the upper guide level are most critical and fatigue-sensitive in the field transit condition, the proposed bracket-stiffened KT-joint is further tested with a simplified fatigue analysis. Jack-up hydrodynamic analysis for motion responses and global finite element analysis for nominal stresses are successively conducted. Finally, comparison of the fatigue strength among three different KT-joints and fatigue life estimation of the proposed KT-joints are obtained. The main findings from current studies are as follows:

(1) Due to the effect of bracket-stiffening, stress concentration at the most critical point (the crown toe of the chord and upper diagonal brace) of the proposed $\mathrm{KT}$-joint is significantly reduced under both axial and IPB loadings. On the contrary, the effect of brace gap increase on the alleviation of stress concentration is not much. It is concluded that the proposed bracket-stiffened KT-joint has the most superior fatigue strength among the three design scenarios of overlapped KT-joints.

(2) According to the industrial guidelines of the simplified fatigue assessment, the proposed KT-joint is successfully applied to fatigue life estimation of jackup leg structures in the field transit condition. Joints A @ FWD Leg and A @ STBD Leg (also A @ PORT Leg due to the symmetry) are most critical in terms 
of the estimated fatigue life. Since quite a few conservative measures have been taken in this study, the obtained results can serve as guides or references in practical engineering applications.

(3) Since the main purpose of this study is to provide an idea of joint design to improve the fatigue performance of two-planar overlapped tubular KT-joints, the developed models and conducted analyses are mainly based on the results of finite element modeling. The fatigue strength model and fatigue life prediction model need to be calibrated by laboratory or field test results. In addition, the configuration of the added brackets is fixed. Parametric studies on the bracket dimension, location in relative to the brace, and shape are recommended for future work.

\section{Data Availability}

The data used to support the findings of this study are available from the corresponding author upon request.

\section{Conflicts of Interest}

The authors declare that they have no conflicts of interest.

\section{Acknowledgments}

This work is supported by the National Natural Science Foundation of China (Grant no. 11872190), the Six Talent Peaks Project in Jiangsu Province (Grant no. 2017-KTHY-010), and the Research Start-Up Foundation of Jinshan Distinguished Professorship at Jiangsu University (Grant no. 4111480003).

\section{References}

[1] J. Zhang, C. G. Koh, T. N. Trinh, X. Wang, and Z. Zhang, "Identification of jack-up spud can fixity by an output-only substructural strategy," Marine Structures, vol. 29, no. 1, pp. 71-88, 2012.

[2] DNVGL-RP-C104, Self-Elevating Units, DNV GL AS, Bærum, Norway, 2015.

[3] M. Efthymiou and S. Durkin, "Stress concentrations in $\mathrm{T} / \mathrm{Y}$ and gap/overlap K-joints," in Proceedings of the 4th International Conference on Behaviour of Offshore Structures, Delft, The Netherlands, 1985.

[4] S. A. Karamanos, A. Romeijn, and J. Wardenier, "Stress concentrations in tubular gap K-joints: mechanics and fatigue design," Engineering Structures, vol. 22, no. 1, pp. 4-14, 2000.

[5] P. T. Myers, F. P. Brennan, and W. D. Dover, "The effect of rack/rib plate on the stress concentration factors in jack-up chords," Marine Structures, vol. 14, no. 4-5, pp. 485-505, 2001.

[6] W. M. Gho, F. Gao, and Y. Yang, "Load combination effects on stress and strain concentration of completely overlapped tubular K(N)-joints," Thin-Walled Structures, vol. 43, no. 8, pp. 1243-1263, 2005.

[7] F. Gao, "Stress and strain concentrations of completely overlapped tubular joints under lap brace OPB load," ThinWalled Structures, vol. 44, no. 8, pp. 861-871, 2006.

[8] J. Yang, Y. Shao, and C. Chen, "Static strength of chord reinforced tubular Y-joints under axial loading," Marine Structures, vol. 29, no. 1, pp. 226-245, 2012.
[9] H. Ahmadi, M. A. Lotfollahi-Yaghin, and S. Yong-Bo, "Chord-side SCF distribution of central brace in internally ring-stiffened tubular KT-joints: a geometrically parametric study," Thin-Walled Structures, vol. 70, pp. 93-105, 2013.

[10] G. Liu, X. Zhao, and Y. Huang, "Prediction of stress distribution along the intersection of tubular T-joints by a novel structural stress approach," International Journal of Fatigue, vol. 80, pp. 216-230, 2015.

[11] H. Ahmadi and A. Ghaffari, "Probabilistic assessment of degree of bending in tubular X-joints of offshore structures subjected to bending loads," Advances in Civil Engineering, vol. 2015, Article ID 518450, 12 pages, 2015.

[12] H. Nassiraei and P. Rezadoost, "Stress concentration factors in tubular T/Y-joints strengthened with FRP subjected to compressive load in offshore structures," International Journal of Fatigue, vol. 140, Article ID 105719, 2020.

[13] H. Nassiraei and P. Rezadoost, "Parametric study and formula for SCFs of FRP-strengthened CHS T/Y-joints under out-of-plane bending load," Ocean Engineering, vol. 221, Article ID 108313, 2021.

[14] H. Nassiraei and P. Rezadoost, "Stress concentration factors in tubular T/Y-connections reinforced with FRP under in-plane bending load," Marine Structures, vol. 76, Article ID 102871, 2021.

[15] S. A. Karamanos, A. Romeijn, and J. Wardenier, "Stress concentrations in multi-planar welded CHS XX-connections," Journal of Constructional Steel Research, vol. 50, no. 3, pp. 259-282, 1999.

[16] S. Chiew, C. K. Soh, and N. W. Wu, "General SCF design equations for steel multiplanar tubular XX-joints," International Journal of Fatigue, vol. 22, no. 4, pp. 283-293, 2000.

[17] S. A. Karamanos, A. Romeijn, and J. Wardenier, "Stress concentrations in tubular DT-joints for fatigue design," Journal of Structural Engineering, vol. 126, no. 11, pp. 1320-1330, 2000.

[18] S. A. Karamanos, A. Romeijn, and J. Wardenier, "SCF equations in multi-planar welded tubular DT-joints including bending effects," Marine Structures, vol. 15, no. 2, pp. 157-173, 2002.

[19] Y. Jiang, K. Yuan, and H. Cui, "Prediction of stress concentration factor distribution for multi-planar tubular DTjoints under axial loads," Marine Structures, vol. 61, pp. 434-451, 2018.

[20] A. M. van Wingerde, J. A. Packer, and J. Wardenier, "Simplified SCF formulae and graphs for CHS and RHS K- and KK-connections," Journal of Constructional Steel Research, vol. 57, no. 3, pp. 221-252, 2001.

[21] C. Woghiren and F. Brennan, "Weld toe stress concentrations in multi-planar stiffened tubular KK joints," International Journal of Fatigue, vol. 31, no. 1, pp. 164-172, 2009.

[22] H. Ahmadi, M. A. Lotfollahi-Yaghin, and M. H. Aminfar, "Distribution of weld toe stress concentration factors on the central brace in two-planar CHS DKT-connections of steel offshore structures," Thin-Walled Structures, vol. 49, no. 10, pp. 1225-1236, 2011.

[23] H. Ahmadi, M. A. Lotfollahi-Yaghin, and M. H. Aminfar, "The development of fatigue design formulas for the outer brace SCFs in offshore three-planar tubular KT-joints," ThinWalled Structures, vol. 58, pp. 67-78, 2012.

[24] H. Ahmadi and E. Zavvar, "The effect of multi-planarity on the SCFs in offshore tubular KT-joints subjected to in-plane and out-of-plane bending loads," Thin-Walled Structures, vol. 106, pp. 148-165, 2016.

[25] X. L. Zhao, S. Herion, J. A. Packer et al., Design Guide for Circular and Rectangular Hollow Section Welded Joints under 
Fatigue Loading, CIDECT Publication, Karlsruhe, Germany, 2001.

[26] EN 1993-1-9, Design of Steel Structures-Part 1.9: Fatigue, CEN, Bruxelles, Belgium, 2005.

[27] C. K. Lee, S. P. Chiew, S. T. Lie, T. Sopha, and T. B. N. Nguyen, "Experimental studies on stress concentration factors for partially overlapped circular hollow section K-joints," Advanced Steel Construction, vol. 5, pp. 481-499, 2009.

[28] W. M. K. Tizani, K. O. Yusurf, G. Davies, and N. J. Smith, “A knowledge based system to support joint fabrication decision making at the design stage-case study for CHS trusses," in Proceedings of the 7th International Symposium on Tubular Structures, Miskolc, Hungary, 1996.

[29] J. G. Bouwkamp, "Concept of tubular-joint design," ASCE Journal of the Structural Division, vol. 90, 1964.

[30] S. Dharmavasan and L. D. Seneviratne, "Stress analysis of POCHS K-joints, fatigue and crack growth in offshore structures," The Institution of Mechanical Engineers, vol. 2, pp. 17-30, 1986.

[31] C. K. Lee, S. P. Chiew, S. T. Lie, and T. Sopha, "Comparison of fatigue performances of gapped and partially overlapped CHS-joints," Engineering Structures, vol. 33, no. 1, pp. 44-52, 2011.

[32] N. L. Pang, X. L. Zhao, F. R. Mashiri, and P. Dayawansa, "Fullsize testing to determine stress concentration factors of dragline tubular joints," Engineering Structures, vol. 31, no. 1, pp. 43-56, 2009.

[33] W. W. Yang, S. T. Li, R. H. Yan, and Y. Q. Suo, "Experimental study on hysteretic behavior of double-plate reinforced overlapped K-joints," Advances in Civil Engineering, vol. 2020, Article ID 3183206, , 2020.

[34] F. Gao, B. Hu, and H. P. Zhu, "Parametric equations to predict LJF of completely overlapped tubular joints under lap brace axial loading," Journal of Constructional Steel Research, vol. 89, pp. 284-292, 2013.

[35] F. Gao, B. Hu, and H. P. Zhu, "Local joint flexibility of completely overlapped tubular joints under in-plane bending," Journal of Constructional Steel Research, vol. 99, pp. 1-9, 2014.

[36] F. Gao and B. Hu, "Local joint flexibility of completely overlapped tubular joints under out-of-plane bending," Journal of Constructional Steel Research, vol. 115, pp. 121-130, 2015.

[37] J. Zhang, J. Jiang, W. Shen, and Y. Luo, “A novel framework for deriving the unified SCF in multi-planar overlapped tubular joints," Marine Structures, vol. 60, pp. 72-86, 2018.

[38] ANSYS, ANSYS Release 15.0 Documentation, ANSYS, Canonsburg, PA, USA, 2013.

[39] R. W. Prastianto, Y. S. Hadiwidodo, and I. F. Faudi, "Stress concentration factor of a two-planar double KT tubular joint due to in-plane bending loading in steel offshore structures," in Proceedings of the MATEC Web of Conferences, vol. 177, Amsterdam, Netherlands, 2018.

[40] DNVGL-RP-C203, Fatigue Design of Offshore Steel Structures, DNV GL AS, Bærum, Norway, 2016.

[41] WAMIT, WAMIT User Manual 6.3, WAMIT, Chestnut Hill, MA, USA, 2006

[42] S. K. Chakrabarti, Handbook of Offshore Engineering, Elsevier, Amsterdam, Netherlands, 2005.

[43] 0030/ND Rev 4, Guidelines For Marine Transportation, GL Noble Denton, Loughborough, UK, 2010.

[44] DNVGL-RP-C205, Environmental Conditions and Environmental Loads, DNV GL AS, Bærum, Norway, 2016.
[45] SACS, Structural Analysis Computer System, version 5.3, SACS, Decatur, GA, USA.

[46] ABS FAOS, Guide for the Fatigue Assessment of Offshore Structures, ABS, Spring, TX, USA, 2003.

[47] ABS Commentary on FAOS, Commentary on the Guide for the Fatigue Assessment of Offshore Structures, ABS, Spring, TX, USA, 2003. 